\title{
Francesco-Alessio Ursini* \\ General location across languages: On the division of labour between functional and lexical items in spatial categories
}

https://doi.org/10.1515/tlr-2020-2053

\begin{abstract}
In many languages, it is possible to describe the location of any entity with respect to a landmark object without specifying the exact place that the locatum occupies (e.g. English at in at home). Such vocabulary items usually contrast with items that belong to the same categories but have more restricted senses (e.g. on top of in on top of the shelf). Thus, the degree of "abstractness" that such spatial case markers can convey usually depends on the organization of the lexicon and grammar of spatial terms in each language. The goal of this paper is to explore these properties across a small sample of languages and offer an account of this variation that is connected to previous theories of spatial case markers (e.g. adpositions). Our key proposal is that the morpho-syntactic structure of spatial case markers and their phrases can license a clear division of labour between functional and lexical spatial senses. However, intermediate solutions blurring categories and semantic boundaries are shown to be possible. We formalize this proposal via a fragment of Lexical Syntax, and show that degrees of distinction between 'functional' and 'lexical' sense types and categories can be modelled via a unified account.
\end{abstract}

Keywords: spatial case markers, adpositions, case morphemes, general location, basic locative constructions, Lexical Syntax

\section{Introduction}

Adpositions and case affixes covering spatial senses, or spatial case markers, have recently received renewed attention (Asbury 2008; Cinque and Rizzi 2010; Dryer 2013a; Hagége 2010; Levinson 2003). The study of these categories has often involved the formulation of "grammars of space" outlining their properties within a language (Levinson and Wilkins 2006). Three key results emerge from these

\footnotetext{
*Corresponding author: Francesco-Alessio Ursini, School of Chinese Language and Literature, Central China Normal University, No. 152 Luoyu Road, Wuhan, China,

E-mail: ursini@mail.ccnu.edu.cn, https://orcid.org/0000-0001-7042-3576
}

O Open Access. (C) 2020 Francesco-Alessio Ursini, published by De Gruyter. (cc)BY licensed under the Creative Commons Attribution 4.0 International License. 
studies. First, spatial markers systematically interact with other spatial categories, e.g. spatial nouns, particles, co-verbs, to convey spatial senses (DeLancey 2005; Dryer 2013b; Hagège 2010; Haspelmath 1997). Second, morphological and (semantic) sense complexity usually dovetail (Lestrade 2010). Third, these relations seem to determine how the grammars and "lexica" of space are organized and interact (Levinson and Meira 2003: 489).

An indirect consequence of these results has been foreshadowed in Lehmann (1985: 103-104)'s analysis of grammaticalization patterns involving adpositions (cf. also Lestrade 2010; Zwarts 2010). Many languages often have a small number of simple adpositions (i.e. mono-syllabic, mono-morphemic items) that can be used to refer to more than one location. Morphologically complex (i.e. multi-syllabic, multi-morphemic) adpositions are usually more numerous and refer to narrowly defined locations. One illustrative English example is as follows. At captures a relation between a landmark entity (or ground) and a locatum (or figure: Talmy 1978, 2000: Ch. 1). This relation does not individuate a single location that the figure occupies (Coventry and Garrod 2004: 68-74; Evans 2009; Feist 2006, 2008; Herskovits 1986; Huddleston and Pullum 2002: 719-720). Rather, it implies that the figure may be in any of a heterogeneous set of possible locations. Conversely, in front of individuates a location more narrowly defined along the 'front' axis of a ground. Consider (1)-(2):

(1) Mario is waiting at the pub.

(2) Mario is waiting in front of the pub.

In (1), at can be conceived as a simple preposition that can be used to describe Mario's position as being either in front, or behind, or to the left or right side, and so on. Instead, the complex preposition in front of only describes Mario's position as along a pub's front axis. In line with Lehmann's observation, at is a simple preposition that can refer to several distinct locations, including the 'front' location. Instead, in front of is a complex preposition that can refer to one restricted type of location.

Crucially, (1)-(2) also show that at and in front of do not share any grammatical and lexical properties beyond their (spatial) sense type and category. However, pairs such as at and in front of also suggest that simple and complex prepositions can stand in more systematic, lexical and paradigmatic relations. If at can be used to describe a ground being involved with a figure, then in front of restricts this relation to the front part of the ground (Levinson and Meira 2003: 509-510; Feist 2008). Thus, in, front and of can be conceived as supplementary morphological material selecting a more restricted spatial sense in a compositional manner and indirectly establishing that these two prepositions are lexically related.

To capture this sense distinction, we use the term "functional" for spatial case markers that denote spatial relations involving more than one (possibly, any) 
location that the figure can occupy. We then use the term "lexical" for spatial case markers that denote more restricted relations, possibly involving one distinctive location. For spatial case markers, apparently distant frameworks converge in assuming that grammatical items' key "function" is to capture abstract spatial relations (e.g. Cinque and Rizzi 2010; Hagége 2010). Thus, at seems to qualify as typical "functional" preposition within English given its ability to capture an abstract, non-restricted spatial relation. Items including "exapted” lexical elements such as front restrict such relations to specific locations via their lexical content. Hence, in front of and other morphologically more complex prepositions can be labelled "lexical" prepositions.

Morphological complexity and degree of lexical content seem to be related, a fact that may be connected to Zipf (1949)'s law. Simple prepositions such as at and on may carry broader or more general senses, so their mono-morphemic structure is a reflex of their (possible) higher frequency of use. Complex prepositions involve structures that select more restricted senses, so their complexity may also determine their lower frequency. If this is the case, there can be a relation between the degree of abstractness that prepositions and other spatial case markers can carry and the structure of the spatial lexicon of a language. The categories making up the grammar of space of a language can determine the organization of its lexicon in principled ways. For English, these lexical relations can be implicit (cf. at and in front of ) or explicit (e.g. on and on top of ). For other languages, these relations may follow different patterns that seem mostly unaccounted for, so far.

We believe that at least four empirical questions arise from this flexibility of the lexicon. The first question is which categories among spatial case markers can cover functional senses, of the type that at and similar other markers can carry (Dryer 2013a). The second question is which categories covering lexical senses (e.g. in front of, on top of ) are morpho-syntactically and semantically related to spatial case markers (Lestrade 2010: Ch. 6). The third question is how these categories interact with form sentences such as (1)-(2) (Levinson and Wilkins 2006: Ch. 14). The fourth question is whether one can offer a unified theoretical, crosslinguistically sound account that can capture these pre-theoretical notions of general and specific senses, and their relation to morpho-syntactic complexity.

The goal of this paper is to answer these four questions, thereby offering a theory of spatial case markers that can capture this division of labour in a compact manner. We propose that case markers qua grammatical, morphologically simple categories can head phrases in which the head establishes an abstract relation holding between figure and ground. An optional "restrictor" (e.g. in front in in front of ) possibly consisting of several morphemes can narrow the sense of this relation to a more content-based, lexical sense. We also propose that divergences from this isomorphic mapping stem from the division of labour between grammar and 
lexicon of spatial case markers. Anticipating matters a bit, languages that "conflate" spatial categories and their senses into a single domain (e.g. prepositions) seem to also conflate this sense distinction in a systematic manner.

We formulate our analysis in a minimal fragment of Lexical Syntax (Hale and Keyser 2002). By pursuing this goal, we also address two possible contributions to theories of spatial case markers. One is to typological theories of lexical organization (Lehmann 1985; Stolz 2007). The other is to generative theories on their morpho-syntactic structure and semantic interpretation (e.g. Cinque and Rizzi 2010). We thus offer the first empirical and theoretical account that attempts to connect the presence of simple and complex spatial case markers in languages with their ability to cover general and specific senses. ${ }^{1}$ The paper is organized as follows. Section 2 presents previous analyses of this problem and motivates a solution to this theory. Section 3 presents data from a convenience sample of languages. Section 4 presents our account; Section 5 compares this account with previous proposals. Section 6 concludes.

\section{Previous analyses}

In this section, we first discuss previous semantic works, and then move onto morpho-syntactic accounts. Although we will pursue a generative account, we haste to note that several works relevant to our goal fall outside this framework. Our goal in reviewing this literature is thus not only shedding light on previous proposals regarding this topic, but also highlighting converging themes in apparently diverging frameworks.

The semantics of case markers and their senses has been the topic of many studies across different frameworks. A general assumption is that spatial senses can be organized into certain sense types, defined as classes of senses describing certain spatial relations. Standard taxonomies within formal (model-theoretic) semantics focusing on adpositions propose a distinction between locative and directional adpositions, i.e. adpositions covering senses describing location and (possibly) directed motion, respectively (e.g. English at vs. to). Locative adpositions are then divided into non-projective and projective senses (e.g. in vs. behind),

\footnotetext{
1 Let us note here that in Levinson and Meira (2003), but also in previous typological works (e.g. Lehmann 1985), this distinction is phrased in terms of "general" and "specific" senses. We find that the use of this other pair of labels may be more intuitively appealing (i.e. lexical prepositions tend to refer to unique/specific locations). However, we acknowledge that their labels create a degree of terminological confusion that we wish to avoid (cf. this notion of specificity with specificity in DPs). We thank an anonymous reviewer for raising the issue.
} 
with "end-point" senses (e.g. on top of) being a third possible type (Bennett 1975; Bowerman and Pederson 1992; Cresswell 1978; Gehrke 2008; Haselbach 2017; Jackendoff 1983, 1990; Zwarts 2005, 2008; Zwarts and Winter 2000).

Several works have also investigated how spatial categories can cover more than one sense type, thus displaying forms of polysemy. One example is the analysis of how languages lexicalise directional and locative senses via verbs or prepositions, thus distributing along a "verb-framed" to "satellite-framed" continuum (e.g. Mateu 2002; Slobin 1996, 2004; Talmy 1983, 1985, 2000). Other well-studied topics are the sense types associated to body part terms (cf. the papers in Enfield et al. 2006), types of place names (e.g. Burenhult and Levinson 2008; Stolz et al. 2017), topological notions (Bowerman and Choi 2001; Bowerman and Pederson 1992), and reference systems (e.g. Levinson and Wilkins 2006). Thus, the senses and sense types making up the spatial semantic domain are relatively wellstudied. However, works focusing on sense relations between "functional" and "lexical" senses are sparser, to a certain extent.

A work that explicitly addresses these relations is Levinson and Meira (2003). This work proposes a thorough taxonomy of spatial senses ("concepts", in the paper), organized in terms of increasing lexically specific concepts. The most abstract or "general" spatial concept found across languages is glossed as AT. When a case marker covers this concept, no information is expressed beyond the figure being located with respect to the ground. If languages distinguish further spatial concepts, then they minimally divide between the concepts IN and $\mathrm{AT}_{1}$, i.e. 'internal' and 'external' location. The concept AT thus acts as a residual category: when a concept captures a specific spatial relation, $\mathrm{AT}_{\mathrm{n}}$ covers the other possible relations (cf. Berlin and Kay's 1969 “COOL” concept for colour terms). The resulting implicational hierarchy of senses stemming from this analysis is in (3):

$$
\mathrm{AT}_{4}, \mathrm{ON}-\mathrm{TOP}, \mathrm{ATTACHED}, \mathrm{NEAR} . . \leqslant \mathrm{INSIDE}, \mathrm{IN}, \mathrm{ON}_{1}, \mathrm{AT}_{3} \preccurlyeq \mathrm{IN}_{1}, \mathrm{AT}_{2} \preccurlyeq \mathrm{AT}
$$

The symbol “ $\leqslant$ ” stands for the implication relation. If a concept $x$ is attested in a language (i.e. the left argument in e.g. $x \preccurlyeq y$ ), then at least one concept $y$ is attested higher in the hierarchy (i.e. the right argument). For instance, English has an item covering the concept ON-TOP (i.e. on top of ), so it must also have an item covering the concept ON (i.e. on). Hence, an increasingly abstract or "general" sense for a spatial case marker can be defined when a marker can refer to more than one location, and possibly to any location with respect to a ground. Conversely, "specific" senses are defined as senses that refer to possibly one location with respect to a ground (e.g. its 'front'). Since this hierarchy corresponds to a chain of implication relations, it establishes that the existence of more specific spatial concepts implies the existence of a general concept AT, and increasingly less general $\mathrm{AT}_{\mathrm{n}}$ concepts (e.g. OUTSIDE or $\mathrm{AT}_{3}$, as opposed to INSIDE). Spatial case 
markers can cover any of these senses, and the corresponding items can display differing degrees of sense specificity/generality.

A proposal that follows a similar philosophy but offers a different taxonomy is found in Vandeloise (2010) (cf. also Aurnague and Vieu 2015 for a closely related account). ${ }^{2}$ This work suggests that the emergence of lexical items can be based on language-external and language-internal variation principles. For spatial categories, this entails that e.g. adpositions can be associated to spatial, non-linguistic concepts (i.e. language-external). For instance, English at is associated to the general concepts of "SPATIAL RELATION" and "PROXIMITY". The emergence of further lexical items proceeds by internal principles of division and union. For instance, English in expresses the union of "INCLUSION" and "CONTAINMENT" concepts, while adpositions in front of and behind divide the semantic space of projective senses into more specific senses. Although it proposes a sensibly different taxonomy of spatial senses from Levinson and Meira (2003), this work also suggests that spatial case markers can emerge in language via the internal drive to cover increasingly restricted senses.

Model-theoretic approaches have also proposed fine-grained analyses of prepositions' senses. Proposals include prepositions denoting geometric entities such as paths (Cresswell 1978; Verkuyl and Zwarts 1992), regions (e.g. Haselbach 2017; Nam 1995; Wunderlich 1991), and vectors (Svenonius 2008; Zwarts and Winter 2000). Cognitive semantics studies have instead investigated the polysemy of prepositions, suggesting that each preposition can cover a network of interrelated senses (e.g. Brugman 1988; Evans 2009; Evans and Tyler 2004; Lakoff 1987). It is also well-known that other spatial categories can contribute to capturing spatial senses across languages. However, cross-linguistic and cross-categorial studies are rare. The standard praxis is to offer language-specific accounts of the data (Wunderlich 1991 on German postpositions; Zwarts 1997 on Dutch prepositions; Bohnemeyer 2012 on Yucatec particles). Nevertheless, formal and cognitive approaches have offered fine-grained analyses that highlight how spatial prepositions and markers can usually involve complex, tightly related senses.

These different frameworks also converge on considering two facts about the semantic contribution of spatial markers as uncontroversial. First, simple adpositions, case markers, and co-verbs usually capture "basic" geometrical relations, often with a force-dynamic (i.e. non-spatial) dimension (e.g. Bowerman and Choi 2001; Bowerman and Pederson 1992; Talmy 1988). Second, parts of speech

2 This work also discusses at length why a causal/mechanical dimension plays a crucial role for the analysis of spatial markers' meanings/senses (cf. also Coventry and Garrod 2004). We must gloss over this topic to maintain our discussion compact, but we acknowledge that our discussion only focuses on the spatial dimension of meaning. 
referring to body parts (e.g. localisers, postpositions) are often co-opted to refer to locations relative to a ground location (Enfield 2006; Hagége 2010; Heine 2003). Thus, spatial case markers seem to denote "layered" relations. A first layer establishes the type of relation between figure and ground; a second layer restricts the range of locations involved in this relation, and usually co-opts other spatial categories for this purpose.

Crucially, these semantic approaches leave aside the relation between lexical/ semantic and grammatical structure. For instance, Levinson and Meira (2003: 496-497) and Vandeloise (2010: 175) observe that sense "specificity" is often related to morphological complexity, but do not attempt to spell out the details. Furthermore, Levinson and Meira (2003) observe that morphologically simple grammatical markers tend to have abstract senses ("general", in their terminology). However, this proposal does not explore this relation between "form" and "content" beyond proposing a perhaps vague distinction between "general" and increasingly "specific" senses. Thus, these works leave open the questions outlined in the introduction, given their focus on the semantic side of the data.

Model-theoretic analyses do not sharply distinguish between "functional" and "lexical" spatial senses. However, some proposals observe that certain components of meaning are "shared" amongst prepositions, so they should feature in their sense definitions. For instance, Zwarts and Winter (2000) suggest that projective prepositions (e.g. in front of, on top of, behind) always involve an 'external' relation holding among a set of vectors, ground and figure connected via this set. A further preposition-specific condition on these vectors, e.g. that they are 'front' vectors in the case of in front of, completes their senses. Subsequent proposals attempt to spell out a compositional analysis of each morpheme in complex prepositions (Matushansky and Zwarts 2019; Svenonius 2008). However, these proposals gloss over the relation between sense specificity and morphological complexity, and whether they can offer insight on the organization of spatial lexica.

We now turn to syntactic accounts. The literature on case affixes is voluminous, so we cannot possibly review it in its entirety here. Nevertheless, recent works have discussed distinctions among prepositions, postpositions, and cases (e.g. Hagège 2010; Lestrade 2010; Libert 2006, 2013; Malchukov and Spencer 2011). Studies on co-verbs (Aikenvhald and Dixon 2006), and liminal categories such as particles and spatial nouns (DeLancey 2005; Levinson 1994, 1996) have also discussed how these categories can cover spatial senses. A well-known result is that spatial categories are tightly connected via their diachronic origins. Since grammaticalization theory can offer important insights on how the diachronic and 
syntactic side of the discussion hinges on the observed synchronic patterns, we briefly discuss its core assumptions.

In grammaticalization theory, words are distinguished between lexical and grammatical items. Grammatical items capture grammatical relations between lexical items (e.g. auxiliary verbs) or combine with lexical items to derive new forms (e.g. derivational and inflectional morphemes). Grammaticalization can be defined as the process whereby a lexical item develops grammatical functions, loses its lexical content, and becomes a grammatical item over time (Heine and Kuteva 2007: Ch. 1). Adpositions and spatial/grammatical cases, in standard grammaticalization accounts, emerge from nouns and verbs that lose their original sense and develop more abstract functions. For instance, nouns and verbs are represented as source categories from which adpositions can emerge via grammaticalization. Consider the cline in (4), in which the symbol " $\leqslant$ ” is used to represent source and target categories for this process (Heine and Kuteva 2007; König 2011; Lehmann 1985):

\section{Relational noun $\preccurlyeq$ Particle,}

Adverb $\preccurlyeq$ Postposition $\preccurlyeq$ Preposition $\preccurlyeq$ Agglutinative case $\preccurlyeq$ Fusional case

There are several clines that have been proposed to account the grammaticalization patterns connecting (spatial) relational nouns to spatial cases (e.g. Blake 2001; Bybee 1985; Croft 2003; Heine and Kuteva 2007; Heine et al. 1991; Hopper and Closs Traugott 2003; Rhee 2004; Stassen 2009; Svorou 1994). Works that have focused on this category provide a fine-grained cline in which particles, adverbs and postpositions emerge before prepositions and spatial case morphology, as the cline in (4) shows. Thus, these works indirectly predict that functional spatial categories can emerge as grammatical categories involving more abstract senses (e.g. prepositions such as in). Nevertheless, these categories are related to lexical spatial categories (e.g. relational nouns such as front), which find their senses in their ability to carry lexical content.

A different, inherently synchronic perspective on these categories is offered in formally oriented analyses. Generative syntax has amply investigated the properties of spatial case markers, but other frameworks have also investigated these categories (e.g. Tseng 2000; Vincent 1999). Nevertheless, many works we draw data from are generative in nature, and our account will be framed in one variant of the Minimalist programme. Hence, it is appropriate to focus on this type of analysis from here onwards.

Classic generative analyses of adpositions suggest that this category can be decomposed into two functional heads, originally known as the Path and Place heads (e.g. Jackendoff 1983, 1990; Koopman 2000; van Riemsdijk 1978). Place heads describe the "place" (i.e. location) that a figure occupies with respect to a 
ground; Path heads whether this relation involves motion or a lack thereof. In subsequent recent work within the "Cartography" approach, this structure has been partitioned into a sequence of functional heads, one per identifiable morpheme in an adposition (e.g. Cinque and Rizzi 2010; Pantcheva 2011; Radkevich 2010; Svenonius 2010; among many others). By assuming that language-specific categories may offer evidence about language-general available categories, cartographic approaches offer rich sequences of functional heads. The proposed structures for adpositions that the classical and cartographic approaches offer are presented in (5)-(6):
a. [PathP from [PlaceP under [DP the [ sofa ]]]]
b. [PathP to [PlaceP in front of [DP the [ sofa ]]]]
c. [PathP $\varnothing \quad[$ PlaceP at [DP the [ sofa ]]]]
a. [PathP $\emptyset \quad$ [PlaceP in
b. [PathP $\emptyset \quad[$ PlaceP at
[AxPartP front [KaseP of [DP the [ house ]]]]]
[AxPartP $\emptyset \quad[$ KaseP $\varnothing[$ [DP the [ house ]]]]]

The structure in (5a) shows how the bi-partite, classic analysis applies to English "compound" prepositions, i.e. prepositions combining two items that do not standardly form a lexical unit (here, from and under). Crucially, this analysis can be extended to other prepositions by assuming that all complex prepositions project a Place head (e.g. in front of in (5b)). For simple prepositions such as at, at least in their "pure" locative uses (e.g. (1)), the classical analysis proposes that the Path head is silent, and this preposition only realises an abstract "Place" concept. Although counter-examples to this analysis exist (cf. Mario arrives at the station), the classical analysis postulates that a precise correspondence between sense and category exists, in prepositions.

The structure in (6a) offers a conservative cartographic account for the structures of Prepositional Phrases (PPs) (Asbury 2008; Svenonius 2008). A (compound) preposition such as in front of involves a Path, Place, Ax(ial)Part and Kase head, respectively projecting from in, front and of. These structures are partly simplified, as most proposals would include further heads (e.g. Deix(is) for Deictic content: Svenonius 2010). We leave them aside, although in Section 5, we return on this topic once we compare our proposal with cartographic analyses. The structure in (6b) shows that at only projects a Place head, and all other heads project empty morphemes. Thus, it shows that prepositions do not necessarily realize each of their proposed projections.

Overall, typological and generative/formal syntactic frameworks offer important insights on the properties of spatial case markers, and the relations holding between this category and contiguous categories (e.g. spatial nouns). However, both lines of inquiry do not fully investigate the relation between these 
properties and lexical/semantic properties with respect to the functional/lexical distinction. For instance, grammaticalization studies do not investigate how the categories forming the diachronic cline in (4) can synchronically interact in languages and their grammars of space. Consequently, they also do not attempt to analyse whether the emergence of prepositions and other grammatical case markers signals the emergence of abstract or 'general' senses of the type discussed in (3).

Similarly, (5)-(6) show how classic and cartography analyses assume that simple and complex prepositions do not differ in their underlying structure, but rather in which heads they overtly realize. Interestingly, these structures also show that generative analyses of spatial case markers stumble in a quandary. According to this type of analysis, semantic content and overt lexical realization seem to go hand in hand. However, classic and cartographic analyses tend to consider functional and lexical aspects of prepositions to form integrated domains. They thus propose that prepositions, in particular complex items, may combine both types of content (e.g. Jackendoff 1990: Ch. 4; Svenonius 2010: 140). One may thus speculate that 'functional' senses are related to the lack of overt morphemes realizing certain heads with a 'lexical' sense. As for semantic accounts, the organization of spatial lexica as revolving around the 'functional'/'lexical' continuum is left untouched.

Let us take stock. Previous works on case markers, whether they are rooted in functional-typological or formal accounts, have offered analyses that indirectly hint at the relations between complexity, lexical content, and the lexical organization of spatial case markers. However, the precise properties of these relations are still unexplored. Hence, even if we consider the semantic cline in (3) and the pathways in (4) to be connected via the structures in (5)-(6), an open question remains on how grammar and semantic-lexical structures are connected. Furthermore, our initial discussion only mentions a handful of English data. Therefore, it invites the question on what kinds of patterns may be attested across languages, and which accounts are better suited to handle them. In the next sections, we attempt to answer this question.

\section{Methodology and data}

The goal of this section is to present the data that will motivate our account of spatial adpositions and their lexical organization. We use glosses markers (e.g. 'functional') for these senses, to highlight that we address an inherently semantic distinction. For the discussion of our data, we propose a bi-partite typology of languages. As it will become clear from our discussion, languages may differ in 
how their grammar of space captures spatial relations. However, we link this distinction syntactic distinctions in each language. In certain languages, a common pattern is that a marker with a 'functional' sense (e.g. a preposition) introduces a spatial relation, and another spatial category aside the ground NP completes a phrase by introducing a 'lexical' sense. Thus, the semantic distinction between 'functional' and 'lexical' senses is clearly reflected in a distinction between categories covering these senses.

In other languages, however, markers with a 'functional' sense may involve allomorphs capturing this relation, or vocabulary items covering increasingly less 'functional' relations. Hence, the distinction between 'functional' and 'lexical' senses is distributed over a set of morphologically related categories. At the other end of this continuum, some languages may only feature this distinction in certain specific constructions or vocabulary items. Therefore, the same category (e.g. prepositions) may cover both 'functional' and 'lexical' senses and may feature blurry boundaries between simple and complex categories.

We thus propose an analysis of the data based on eight languages. A first group of four languages (Lao, Fongbè, Mandarin, and Tzeltal) displays a generally clear distinction between 'functional' and 'lexical' categories/senses. A second group (Māori, Estonian, Tsez, and Italian) displays increasingly blurrier boundaries between these categories. This small convenience sample does not aim to be typologically exhaustive and could be conceived as presenting a categorial continuum arbitrarily partitioned into two groups. However, via this sample we present an initial overview of the types of grammars and lexica of space and how they can partition this space (Levinson and Meira 2003: 496-499; Levinson and Wilkins 2006: Ch. 1). Note, furthermore, that for lexical/semantic variation, the size and diversity of samples is not a pressing constraint as it is for grammatical variation. The complexity and diversity of lexica across languages usually permits researchers to formulate generalizations even with small samples such as ours (Georgakopoulos and Polis 2018: 22-24; Rakhilina and Reznikova 2016 101-102). Let us make precise some notions, before discussing the data.

For each language, we present an overview of the chief spatial categories, the corresponding lexical and grammatical items, and their grammatical and lexical properties. When case affixes are involved, we distinguish between structural (e.g. ergative, genitive) and semantic (e.g. locative) case affixes, as they display subtly distinct syntactic and semantic properties (Blake 2001; Caha 2009; Lestrade 2010). All examples follow Leipzig glossing rules (Croft 2003: xxiv-xxv), with languagespecific conventions mentioned in each section. We then propose five theoretical assumptions.

First, all examples include (sometimes bare) NPs or DPs that denote various sub-types of discourse referents, entities that can be talked about in discourse 
(Karttunen 1976; Kibrik 2013). Figure and ground are two such sub-types. Second, spatial case markers can involve different sense types, such as 'directional', 'locative' and the other senses discussed in Section 2. These types denote relations between locations, which in turn are types of (spatial) referents that one can refer to, in discourse. Crucially, the 'location' type is the most likely type to be morphologically realized in a language (e.g. Lestrade 2010: Ch. 4). We thus focus on 'location' sense types to investigate the 'functional'/'lexical' sense dimension. ${ }^{3}$ We believe that this distinction can also partition 'directional' senses; we leave the investigation of this matter for future endeavours, however.

Third, we refine the notions of 'functional' and 'lexical' (location) sub-types as follows. A vocabulary item covers a 'functional' sense type if its sense can cover the senses of all the other spatial senses. ${ }^{4}$ While the 'functional' sense item denotes a spatial relation that does not specify which locations are involved in this relation (e.g. at), the 'lexical' sense items select which locations are under discussion (e.g. in front of ). Thus, our discussion of the data aims to show to what degree different spatial categories can have increasingly 'lexical' senses, due to their ability to carry content individuating certain specific locations (Levinson and Meira 2003; Vandeloise 2010).

Fourth, to illustrate the types of senses attested in each language, we use two types of sentences. One involves basic declarative sentences ("Basic Locative Constructions" or BLCs: e.g. Stolz et al. 2017). The other involves sentences involving ellipsis of the ground DP. When this form of ellipsis occurs, the governing head is usually also elided (Merchant 2001: Ch. 2; 2004; Svenonius 2006, 2010). The remaining constituent or remnant displays an adverbial-like distribution and refers to either one location or to a "projection" related to the implicit ground (e.g. in front), viz. (7):

$$
\text { Mario sits in front (of the desk) }
$$

3 Two points regarding polysemy are crucial, here. First, spatial markers are type-polysemous. Aside a spatial/functional dimension, they can cover temporal, aspectual and metaphoric senses (Evans 2009; Haspelmath 1997; Heine and Kuteva 2007), and predicative/possession relations (Stassen 2009). Second, 'lexical' items can be token-polysemous, since they can cover several, related senses (cf. Tyler and Evans 2003; for English). We only discuss the role of possession relations, because they usually establish a relation between ground NP and a 'specific' location defined as "belonging" to (i.e. part of) the ground's space. We also leave other sense types and tokens aside, for reasons of space.

4 Note that Coventry and Garrod (2004: 66-74) discuss the possibility for English at to also cover senses such as 'under' or 'above', in the opportune context. The "shape" of the ground also plays a role, in licensing these interpretations. We do not discuss this matter further as it would take us too far afield. 
In front involves the combination of the Place head in and the AxPart head front, as part of the complex preposition in front of. When the ground DP is elided, so is the Kase head of. The elided in front appears to act as a single semantic unit referring to the front location of the context-given desk. Classical (generative) and cartographic analyses of adpositions take slightly different stances to the structure of this type of remnants. For our purposes, remnants and the sentences they are part of offer important evidence for the 'functional'/'lexical' sense alternation. ${ }^{5}$ This because they allow us to identify which elements (categories) in complex adpositions/structures carry more specific, lexical-like senses, allowing reference to specific locations. Furthermore, we use the label PP for any phrase with a spatial case marker as a head, to simplify exposition of the data. With these assumptions in place, we can turn to the analysis of the data.

\subsection{First type: “Clear” languages}

We begin our discussion with "clear" languages, i.e. languages in which there is a clear division of labour between categories when 'functional' and 'lexical' sense types are involved.

We start from Lao or Laotian, a tonal language of the Tai-Kadai family, which has a strong isolating morphology and an overall SVO word order (Enfield 2007: Ch. 1, 2010; Kerr 1994). According to Enfield (2004, 2007: Ch. 16), Lao has one verb/ preposition that covers a 'functional' spatial sense in BCLs, juu, and that can head spatial phrases. As a co-verb, it can be the main predicative element in a sentence, viz. (8); as a preposition, it introduces a spatial phrase, viz. (9). Co-verbs are here defined as parts of speech that describe aspectual or temporal values of a verb's underlying event (Aikenvhald and Dixon 2006).

More 'lexical' senses emerge as follows. According to Enfield (2007: 391-395), BLCs can include posture or placement verbs (e.g. nang 'sit'), and “denominal locative markers" specifying the figure's location. While some of the lexical items belonging to this category still have nominal functions (e.g. naa 'front (of)' can combine with classifiers), others lack them (e.g. theng 'top (of)'); irrespective of their distribution, they seem to cover 'projective' senses. The presence of a verb and a denominal locative marker may render juu optional. The ground NP can also undergo ellipsis, thus licensing the occurrence of denominal markers as adverbials

5 It is worth observing that ellipsis of a ground NP targets a non-constituent structure: head P and ground NP do not form a constituent. Hence, it would be more appropriate to discuss the formation of a fragment or gapping, i.e. two sub-types of ellipsis distinct from true argument ellipsis. This aspect is not crucial for our discussion, but see Boone (2014: Ch. 2) for a thorough overview. 
(cf. (10): Simmala and Benjawan 2003: Ch. 2; Enfield 2007: 395-396). The list in (11) presents the two spatial grammatical items of Lao; the list in (12), some of the locative markers acting as chorophorics in this language:

(8) Phen juи talaat.

(=(1085), Enfield 2007)

3SG.PRS be.at market

'She is at the market.'

(9) Phen lin phaj juu talaat.

3SG.PRS play cards be.at market

'She is playing cards at the market.'

(10) Phen juu/nang (juu) naj (huan). ((=1099)/(1102), Enfield 2007) 3SG.PRS be.at/sit (be.at) inside (house)

'She is/sits inside (the house).'

(11) Spatial co-verbs/Prepositions:=\{tiing/nêng 'move', juu 'be at'\}

(12) Denominal Locative markers: $=\left\{\right.$ theng 'above, on top of', lum ${ }^{1}$ 'below, lower than' kòòng ' 'underneath', khaang'beside, side of', naa 'front of, face of', $t a j$ 'downstream, South of',...\}

Overall, these Lao data suggest that the auxiliary verb/preposition juu acts as a grammatical item covering 'functional' spatial senses. The presence of denominal locative markers acting as restrictors guarantees the existence of 'lexical' sense types. Due to the isolating nature of Lao, semantic distinctions transparently map onto these syntactic structures. BLCs can describe 'functional' spatial relations when markers are absent, but their compositional contribution restricts BLCs' senses to a 'lexical' type, in a systematic manner. Thus, if juu acts as grammatical item neatly covering a 'functional' sense, then denominal locative markers cover the 'lexical' spatial senses in this language.

Let us move to Fongbè, a Niger-Congo language mostly spoken in Benin and Nigeria (Capo 1979; Grimes 1996). Fongbè is mostly an isolating language with shades of agglutinative morphology, and a basic SVO order (Lefebvre and Brusseau 2002: Ch. 1). Fongbè features both prepositions and postpositions, which are syntactically distinct from verbs and nouns, respectively (Lefevbre 1989; Lefebvre and Brusseau 2002: Ch. 11). Fongbè has five prepositions: dò 'at', sín 'to' and káká 'up to, until' cover spatial senses. Crucially, dò can act as either a preposition heading a PP, or as an auxiliary verb/co-verb in BLCs. Irrespective of its distribution, dò covers a 'functional' sense (cf. (13)-(14)). Conversely, specific spatial senses are captured via postpositions, which can be divided into two sub-types: those having a cognate noun, and those lacking it (Canac-Marquis 1986; Lefebvre 1989, 1990). We focus on the first sub-type, which includes spatial postpositions. 


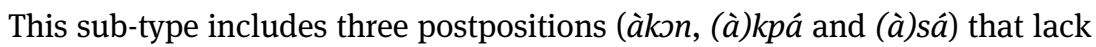
the initial vowel, unlike their cognate nouns. ${ }^{6}$ However, the other postpositions cannot be distinguished from their nominal counterparts, possibly because they lack an initial vowel that can undergo elision. Crucially, Fongbè postpositions can partake in BLCs, thus covering 'lexical' type senses by combining with dò (cf. (15)). They can also have adverbial distribution by involving the elision of ground NP and dò, thereby acting as remnants of the whole PP (Lefevbre and Brusseau 2002: 345). We also offer the list of prepositions and postpositions in (16)-(17):

Kıkú wlán nú dò távò (=(1), Lefebvre \& Brusseau 2002: Ch. 11) Koku write thing at table

'Koku wrote something (while) at the table.'

Kıkú dò nú wlán wé. (=(3), Lefebvre \& Brusseau 2002: Ch. 11) Koku be.at thing writing it.s

'Koku is writing somewhere.'

(15) Kэkú (dò távò) gluwé. (=(2)/(68), Lefebvre \& Brusseau 2002: Ch. 11) Koku (be.at table) under

'Koku is under (the table)/bottom (of the table).'

(16) Spatial Prepositions:=\{dò 'at', sín 'from/out of', káká 'until/up to’ $\}$

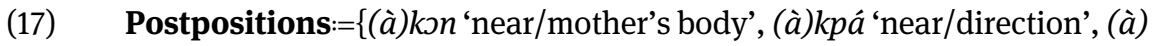
sâ'at the foot of/leg', gluwé 'under/bottom', gon 'at/home', gúdò 'behind/ back', gbè 'inside/voice'...\}

A clarification on the list in (17) is necessary. The proposed glosses for postpositions cover first their 'spatial' senses, and then their 'body part' senses (Lefevbre and Brusseau 2002: 323). While the first 'projective' sense type can be assigned to their postpositional uses, the second type can be assigned to their nominal uses. As (13)-(15) show, however, these senses can co-exist in sentences, even if the projective sense is usually preferred. In ellipsis contexts, their interpretation may retain this ambiguity between 'projective' and 'body part' senses, qua 'specific' sense types that postpositions carry.

Overall, Fongbé data license three conclusions. First, dò acts as the chief 'functional' preposition, even if in its auxiliary verb distribution, it obligatorily

6 Postpositions also seem to share distributional properties with case suffixes and nominal compounds, but only when they carry non-spatial senses (Lefevbre and Brusseau 2002: Ch. 11). We leave this aspect aside. 
selects a postposition in most contexts. Second, postpositions can be distinguished from their body part noun homophonic counterparts, and systematically cover 'lexical' spatial senses and sense types qua restrictors. Third, the syntactic interactions of a 'functional' preposition with 'lexical' postpositions are mirrored in their semantic interaction. Fongbè's lexicon of space is neatly partitioned via its two grammatical categories, pre- and post-positions, with their corresponding distinct 'functional' and 'lexical' senses.

A similar picture emerges in Mandarin, an isolating language that seems to oscillate between SVO and SOV orders (Chao 1968; Li and Thompson 1981; Peyraube 1980; Sun 2006). In Mandarin, spatial senses are conveyed via a set of grammatical items that can act as prepositions but also as co-verbs, like Lao and Fongbè. The preposition zai is mostly used to describe the location of a figure with respect to a ground. The preposition dang is considered near-synonymous with zai, but mostly obsolete in modern Mandarin, so we leave it aside (Chao 1968: 624; Li and Thompson 1981; Sun 2006: 418-419). Zai usually requires another lexical item belonging to the fangweici 'localiser' category to follow the ground NP (viz. (18)), unless the ground is a place name (viz. (19): Sun 2006: 430-431; Huang 2009). In the latter case, zai often acts as a co-verb, taking figure and ground NPs as its arguments.

The syntactic status of localisers is rather controversial. Some works consider prepositions and localisers as forming a discontinuous constituent (i.e. a circumposition: Chao 1968; Koopman 2000; Li and Thompson 1981; van Riemsdijk 1978). Other analyses treat localisers as independent postpositions (e.g. Djamouri et al. 2013; Ernst 1988), or affixal-like elements (e.g. Liu 1998; Zhang 2017). Crucial to our discussion is that localisers can be used as adverbials in discourse contexts licensing ground NP ellipsis (Djamouri et al. 2013; Zhang 2017). First, a localiser must combine with a suffix licensing a nominal-like form (e.g. from shang to shangmian), which normally occurs with possessive marker de. Second, if the ground has been previously introduced in context, then ground NP and de can undergo ellipsis (cf. (20)). The lists in (21)-(22) offer a summary of the items making up these categories:

(18) Zhangsan zuo zai zhuozi shang/( ${ }^{*}$ zai zhuozi Ø). (Li \& Thompson 1981) Zhangsan sit at table on/(*at table $\varnothing)$

'Zhangsan is sitting at/on the table.'
Zhangsan zai Beijing.
((=9), Huang 2009)
Zhangsan is.at Beijing
'Zhangsan is in Beijing.' 
Zhangsan zai (chezi de) shang-mian. (=) (9), Zhang 2017) Zhangsan is.at (car Poss) front-side 'Zhangsan is in front of the car/in the front (of the car).'

(21) Prepositions: $=\{z a i$ 'at', dao 'to', cong 'from', dang 'at', dui 'towards', wang'in direction of', xiang 'in the direction of'\}

(22) Localisers: $=\{l i$ 'in', wai 'out', shang 'on', xia 'down', qian 'front', hou 'behind', zuo 'left', you 'right', pang 'beside', bei 'North', xi 'East', dong 'West', ...

Overall, our discussion of these data invite three conclusions. First, the preposition $z$ ài can also act as a co-verb, but nevertheless captures a 'functional' (location) sense. Second, the near-obligatory presence of localisers follows precise rules, as these items always follow a ground DP (as a bare NP), and cover 'lexical' senses in Mandarin PPs. Third, 'lexical' senses are selected when a localiser restricts the 'functional' sense of zai; a 'functional', abstract sense type is otherwise retained (viz. (19)). Thus, these categories have a precise division of labour in Mandarin grammar and lexicon of space.

We conclude this section by discussing Tzeltal, a Mayan language spoken in the state of Chiapas, Mexico (Becquelin 1997; Brown 2006). The language includes ergative marking on nominal elements and agglutinative morphology, which follows head-marking patterns and a general VOS order. Tzeltal includes roots, affixes, and clitics as basic morpheme units, with inflected roots forming stems or basic words. The preposition $t a$ can be used to introduce spatial, temporal, and other types of adverbial phrases (Brown 1994: 745-746, 2006: 234). The role of $t a$ as a directional or locative marker depends on the verb it combines with. In BLCs, $t a$ occurs with the predicative element ay. While ay can be said to predicate the 'spatial location' of a figure (e.g. the president in (23), the bottle in (24)), ta captures the 'functional' nature of this configuration.

The existence of 'lexical' senses requires a discussion of Tzeltal's spatial grammar and lexicon. Here we only offer a sketch based on previous literature (e.g. Brown 2006; Haviland 1992; Levinson 1994, 1996; Stross 1976). First, Tzeltal includes a set of adverbials based on an "absolute" coordinate system, in which ajk'ol 'uphill' and alan 'downhill' play a key role. While these terms standardly indicate the southern and northern parts of the valley in which Tzeltal is spoken, in their common uses they refer to the "southern" or "northern" locations of a ground. Second, a set of dispositional verbs specify the figure's location when a topological relation is involved. Third, a set of lexical items denoting the ground's "body parts" are used to specify locations as proximal to, or part of the ground as a location. This set is contiguous with, but not identical to relational nouns with 
spatial senses, e.g. $y$-util 'its-inside' (i.e. 'inside'), which carry ergative/genitive case suffixes (e.g. $y$-). We discuss items and distribution in BLCs jointly, via (23)-(29):

Ay-ø ta Tuxtla ya'tikjtatik kunerol. (=(7), Brown 2006) EXIST.3SG.ABS LOC Tuxtla today Mr. President 'The President is in Tuxtla today'

$\begin{array}{lllll}\text { Ay- } \varnothing & \text { ta } & \text { ajk'ol te } & \text { limete-e. } & (=(78), \text { Brown 2006) } \\ \text { EXIST.3SG.ABS } & \text { LOC } & \text { uphill DEF } & \text { bottle-CL }\end{array}$

'The bottle is South'

(25) Waxal-ø ta lum p’in. (=(19), Brown 2006)

Vertically.standing-3SG.ABS LOC ground pot '(The) pot (is) vertically-standing on the ground'

(26) Locative Predicates: $=\{a y$ 'be at, exist', $t a$ 'general location/at' $\}$

(27) Absolute Nouns: $=\{$ ajk'ol 'uphill', alan 'downhill', jejch 'across' $\}$

(28) Dispositional verbs: $=\{$ tek'el 'standing (on legs)', chawal 'lying (face) up',...

(29) Locatives \& Relational nouns: $=\{s$-jol 'its-head/on top of', $s$-pat 'itsback/behind', $x$-ch'uit 'its belly/inside', $y$-akan 'its-foot/bottom of', $y$-anil 'its bottom/underneath',...\}

The list in (26) includes ta as the only 'functional' preposition, and ay as an existential predicate. The list in (27) shows which nouns can introduce locations defined with respect to the 'absolute' system. Their use in (24) describes the bottle as being 'uphill' (i.e. to the virtual South) of an implicit ground. The list in (28) shows instead that dispositional verbs can cover basic topological senses (e.g. 'inclusion', 'support'), while also selecting the spatial structure of their ground (cf. (25)). The list in (29) includes locatives such as s-jol 'on top' and relational nouns such as $y$-anil 'underneath', all sharing underlying projective senses. Note that locative and nouns taking the $y$ - ergative/genitive prefix belong to a different class from those belonging to those taking the $s$ - prefix. These lexical items can refer to a part of a ground and its corresponding location, as the glosses suggest (e.g. 'its back' and 'behind' for spat). Locatives and relational nouns can also license the ellipsis of their ground NPs, as reported in the literature (Brown 2006: 250-251). As we lack explicit examples of ellipsis, we consider adverbial patterns to act as proxy evidence of these items being remnant-like parts of PPs. 
Overall, the preposition ta clearly covers a 'functional' sense, even if it does so by restricting the sense of predicate ay: they jointly describe an abstract, "static" spatial relation. Dispositional verbs, absolute system nouns, and locative/relational nouns qua lexical items can all select 'lexical' senses, in the presence of $t a$. While verbs cover 'topological' senses, nouns cover 'projective' ones. Furthermore, relational nouns seem to act as proxies for spatial categories, at least in their ability to occur as standalone constituents in BLCs lacking a ground. Thus, Tzeltal may involve different morpho-syntactic rules from the other three languages, but it displays a clear division between 'functional' and 'lexical' spatial senses and their relation to a categorial continuum. $T a$ and $a y-\varnothing$ act as grammatical items offering evidence for the existence of 'functional' senses; the other predicate-like categories, of 'lexical' senses. With this result in mind, we can now tackle languages with "blended" systems next.

\subsection{Second type: "Blended" languages}

In this section, we focus on languages that combine or "blend" senses, thereby involving less clear-cut mappings between these types and the categories that cover them.

We begin the discussion with Māori, an Eastern Polynesian language that is mostly spoken in New Zealand. It is usually considered a VSO, isolating language, although its syntactic analysis requires some clarification. Building on previous language-internal analyses of the language (e.g. Bauer 1993, 1997; Biggs 1961, 1969), Harlow $(2001,2007)$ suggest that phrases are the basic syntactic units of Māori grammar. Lexical word forms can act as category-neutral "bases" (i.e. heads) for a phrase. Their combinations with different pre-bases (e.g. definite markers) and particles (e.g. tense markers) determine the resulting phrase types. "Locative" phrases (i.e. PPs) occur in various positions (Harlow 2001: Ch. 7, 2007: Ch. 6). They include a spatial base and a ground NP, and possibly a "locative noun" as a sub-type of pre-base specifying the relative position of the figure.

Māori includes three bases that can cover a 'functional' sense: $i, k e i$ and hei. They respectively conflate this sense and a present, past, and future sense, thus acting as 'spatial' bases with a restricted temporal sense (cf. (30)). These bases can also have an 'ablative' sense when they combine with the verb tae 'arrive', further showing the interaction between prepositions and verbs. When temporal prebases are attested (e.g. kua in (31)), the selected item becomes $i$, thus acting as a pure 'functional' item.

Locative/prepositional phrases in Māori can also include lexical items restricting their senses to projective sense types. Analyses differ on whether these 
lexical items are pre-bases or not, given their homophony with spatial nouns (e.g. Bauer 1993, Harlow 2007; contra Cook 2002; Medeiros 2017; Yamada 2014). Nevertheless, these phrases tend to distribute with $i$ as the principal base, with a second base possibly acting as the main auxiliary verb in the sentence. Furthermore, in the opportune context base and ground NP can be elided, thus leaving pre-bases as adverbial-like remnants with an anaphoric interpretation (cf. (32): Harlow 2007: 150-151). We show the lists of bases and pre-bases in (33)-(34):

I/kei/hei ope Otepoti ia.

(Harlow 2007: 126)

P.at/PRS.at/FuT.at group Dunedin be-3SG

'The group was/is/will be in Dunedin'

Kua tae mai te ope $i$ Rotorua. (Harlow 2007: 156) $\mathrm{P}$ arrive DIR DEF group at Rotorua 'The group has arrived from Rotorua.'

Kei te pukapuka runga ( $i$ te têpu). (Harlow 2007: 157)
P.at DEF book top (at DEF table)
'The book is on top of the table.'

(33) Spatial bases: $=\{i$ 'at, from', $k i$ 'to, towards', $k e i$ 'at, from', hei 'at, from’ $\}$

(34) Spatial pre-bases $:=\{$ runga 'on, top, surface above', roto 'inner part, inside', mua 'front, space in front', raro 'bottom, under', muri 'back, behind', waho 'outer part, outside'...

Overall, Māori data also show a division of labour between a small set of 'functional' spatial bases, and a larger lexical set of 'lexical' pre-bases, as "parts" of a larger "spatio-temporal" phrase. However, the existence of temporallyspecified bases shows that this language does not have a unique 'functional' location marker, unlike the languages belonging to the "clear" type discussed in the previous section.

We now turn to Estonian, a Finno-Ugric language (Abondolo 1998; Comrie 1988; Tauli 1973). It is a mostly SVO language that is slowly moving from an agglutinative to a fusional structure. Estonian, like other Finno-Ugric languages, has a rich inventory of case suffixes, with a clearly delineated locative (i.e. spatial) sub-system (Erelt 2003: Ch. 4; Jürine 2015: Ch. 2). There are six cases traditionally considered as locative, the essive (roughly, 'as') and translative (roughly, 'into a state') sometimes being included in this sub-system (Blevins 2005). The standard list of cases includes the adessive (glossed as 'at/on'), inessive (i.e. 'in'), illative ('into'), allative ('to/onto'), elative ('out of'), and ablative ('from'). Inessive and adessive cases are often characterized as complementary: the inessive case is used 
for 'inner' locations, the 'adessive' case for 'outer' locations (Tauli 1973: Ch. 4). However, both non-linguistic and linguistic factors (e.g. whether the ground is animate or not) affect their selection (Erelt 2003: 134-135).

This complex locative case system is coupled with a postpositional system that can cover 'lexical' senses, partly overlapping with cases' senses in BLCs. For instance, the adessive case can cover an 'inclusion' sense, but also a more abstract sense, depending on the nature of the ground referent (cf. (35)-(36)). Postpositions can also be marked for case, covering the same senses as case-marked ground NPs (e.g. pea-le 'on-LAT' in (37)). Postpositions are usually considered as heads taking ground NPs as their complement, since most of them seem to govern the genitive case, barring exceptions (e.g. partitive with mööda 'along': Palmeos 1985 in Jürine 2015; Erelt 2003; Jürine 2015: 18-21). Postpositions stem from relational nouns denoting body parts and are marked via locative cases. For instance, kõrva-le can be glossed as “ear-ALL” i.e. 'to the ear' or 'beside' (Habicht 2001; Hiietam 2005; Veismann 2009). Postpositions can also act as adverbials/remnants directly combining with verbs, when case-marked ground NPs are elided (cf (38): Erelt 2003: 143; Jürine 2015: 20).

The 'lexical' senses of postpositions can also be evinced from the morphological processes they partake in. Complex items formed as compounds of these nouns with postpositions (e.g. käe-kõrva-l, glossed as "hand-beside-Loc" i.e. 'with') are also a growing, productive category (Jürine 2015). Thus, while the list in (39) offers the set of spatial cases, the non-exhaustive list in (40) covers nominal roots from which postpositions (e.g. kõrval), body part nouns (e.g. käe), and compounds thereof (e.g. käekõrval) can be derived, and form items carrying 'specific' senses:

Flowerbed.ADE grow.3PL flower-PL.NOM

$((=3 a)$, Hietam 2005)

'In the flowerbed there grew flowers.'

(36) Mario on laua-l.

Mario is desk-ADE

(Jürine 2015: 19)

'Mario is at the desk.'

Laua-Ø pea-le/laua-le.

(=(8)-(9), Jürine 2015: 19)

Table-GEN on.LAT/table-ALL

'on the table'

Kampsun on (mantli-Ø) al-l. (=(27), Jürine 2015: 21)

Sweater be.3SG coat-GEN under-ADE

'The sweater is under/below (the coat).' 
(40) Postpositions \& Body Part Nouns:=\{jalg- 'foot/leg', kael- 'neck', Külg'side', pea- 'head', all- 'under', ees- 'front', kõrval- 'ear, kõrval- 'side', käe-kõrva-l 'beside',...

From these data, we can draw three conclusions. First, the adessive case can cover the 'functional' sense. The genitive case seems to be the other "relational" grammatical item covering this structural function in complex phrases, although it is realized via silent morphemes. Second, body part nouns, postpositions and their compounds form a lexical macro-category that can cover 'lexical' senses, seemingly acting as restrictors in Estonian PPs. Third, case suffixation and syntactic combination of cases, postpositions and ground NPs connects 'functional' and 'lexical' senses in a seamless manner. The adessive case can cover a 'functional' sense in some contexts, but it generally covers the more specific 'external location' sense in most contexts. Overall, sense types and categories seem to form a continuum, rather than two clearly distinct domains.

We now discuss Tsez (Dido), a North-East Caucasian Language spoken in the mountains of Daghestan. The Asakh/Asaq dialect acts as an unofficial standard (Alekseev and Rajabov 1991, 1993). Tsez has ergative marking on nominal declensions and a mixed SOV/SVO order, a rich case system and agglutinative/ polysynthetic patterns. Although claims of the existence of dozens of cases have been shown to be inadequate (Comrie and Polinsky 1998), its locative case subsystem is fairly complex. Tsez includes essive, lative and allative/versative series, respectively covering 'location', 'direction (to)', 'origin (from)' and 'direction (towards)' senses (Cysouw and Forker 2009; Polinsky 2015).

Tsez also includes a set of cases covering 'lexical' senses, as the closest markers to a (noun) root. Furthermore, Tsez marks a distal/non-distal distinction via a third case marker, which can occur between these two markers (Comrie 1999; Polinsky 2015: Ch. 5). Each case layer can thus spell out a sense type that, at its highest layer, can cover 'location' and 'direction' senses. Although conventions on labels vary, we present the higher layer as the "directional" case layer, and the lower layer as the "configurational" one. The medial layer covers the "distal/nondistal' alternation via the - $\bar{a} z$ - morpheme (or its absence). For the sake of simplicity, we only present examples in their non-distal, silent form.

Central to our discussion of 'functional' items is the silent morpheme for the essive case. As also observed in the literature, this case is used to cover any locations defined with respect to the ground (Kracht 2002; Polinsky 2015), with the contessive (i.e. - $t$ 'in/among') case only used to express general location with place 
names (Polinsky 2015: 8). The data thus suggest that the "bare" essive and the contessive case, in its restricted distribution, act as 'functional' cases (cf. (41)).

For 'projective' senses, a set of postpositions can further restrict the sense of case-marked ground NPs (Forker 2010; Polinsky 2015: Ch. 4). Postpositions can bear case affixes and have an adverbial distribution, licensing the ellipsis of the case-marked NP. As (43) indirectly shows, the postposition yot 'inside' combines with the ground NP respectively carrying the inessive case (i.e. the possibly elided $q$ 'oc'o $\chi-\bar{a}$ in (43)). Thus, postpositions and locative cases seem related via a form of agreement/semantic selection.

The list in (44) shows all 'directional' cases that can occur in spatial phrases, of which the silent case - $\varnothing$ cover the 'functional' sense. The list in (45) includes locative cases, which mostly cover 'topological' senses. The subessive case, as the list in (46) shows, is an apparent outlier to the analysis of these items as covering topological senses. It can be used to describe a figure being under the ground, so that the ground mechanically blocks the figure. Thus, its topological sense is closer to an antonym of $-\lambda(o)$ 'on', which minimally differs in featuring a frequent, but not obligatory epenthetic vowel:

$$
\begin{array}{lllll}
\text { C'ik'iw } & \text { es-na-bi } & \text { idu- } \varnothing & \text { yot. } & (=(90), \text { Polinsky 2015: 27) } \\
\text { All } & \text { sibling-PL-ABS } & \text { home-ESS } & \text { be.PRS } &
\end{array}
$$

'All the siblings are at home.'

$$
\begin{aligned}
& \text { Yun-o- } \chi^{\prime} \quad \text { ayi } \quad \text { čiw } \chi i-x . \quad \text { (=(97), Polinsky 2015: 111) } \\
& \text { Tree-OS-SUP.ESS bird.ABSIII chirp-PRS }
\end{aligned}
$$

'A bird is chirping on the tree.'

$$
\begin{aligned}
& \mathrm{Li} \quad\left(q^{\prime}{ }^{\prime}{ }^{\prime} \circ \AA-\bar{a}\right) \quad \text { yot } \quad((=109 a), \text { Polinsky: 2015:189) } \\
& \text { Water (barrel-IN.ESs) inside } \\
& \text { 'Water is inside/in the interior (of the barrel).' }
\end{aligned}
$$

(44) Spatial Cases $=\{-\varnothing$ 'at', $-V-r$ 'to', $-\bar{a}-y$ 'from', $-\bar{a} y o r$ 'towards' $\}$

(45) Locative Cases: $=\{\bar{a}-$ 'in (hollow object', $-t$ 'in (mass), among', $-\lambda(o)$ 'on (horizontal)', $-\chi$ 'under (attachment)', $-\chi(o)$ 'at', -de 'near', $-q(o)$ 'on (vertical)' $\}$

(46) Postpositions: $=\{$ adāz/adāy 'in front, ahead' bitor 'away', dandi/ dandir 'across, against', purћo/purtāz 'beside, next to (animate)', $q$ 'ida 'under', ...\}

Overall, Tsez data license two conclusions on the fine-grained picture of the 'functional' to the 'lexical' continuum. First, the silent morpheme seems to cover the 'functional' sense, as a careful analysis of case forms suggests. However, the 
wealth of locative cases covers more specific senses, thus being subject to (semantic) agreement patterns with postpositions, which usually cover 'projective' (i.e. 'lexical') senses. Postpositions, in turn, act as the internal markers of Tsez PPs, which include a ground NP marked for case. Second, locative cases, much like deixis suffixes, seem to act as derivational suffixes covering 'lexical' content. Hence, the morpho-syntactic interaction between cases and postpositions mirrors their systematic interaction in defining senses of increasing specificity.

We conclude this section with Italian, from the Indo-European family of ItaloDalmatian (Romance) languages (Ledgeway 2016; Maiden and Parry 1997). Its ancestor Latin was a free order language in which prepositions and case markers systematically interacted (Vincent 1999). Modern Italian is a fusive, SVO language that apparently lacks a case system, and mostly conveys spatial senses via a dedicated set of prepositions. Italian reference grammars often distinguish between simple (or primary) and complex (or secondary) prepositions (e.g. Rizzi 1988: 496-530). Simple adpositions are mono-syllabic and can act as heads combining with complement noun phrases (e.g. $a$, in). Complex prepositions involve the combination of one or two simple prepositions with one "spatial noun”. These are usually defined as nouns that can describe body parts, and their corresponding locations (Hagége 2010: Ch. 2; Levinson 1994, 1996). For instance, di fronte $a$ 'in front of' includes the simple prepositions $d i$ and $a$, combining with the noun fronte (Garzonio and Rossi 2016); the NP la fronte 'the front' refers to a body part.

Italian prepositions can cover either directional or locative sense types: verbs can select either sense (Folli 2002, 2008; Talmy 1985). Irrespective of the 'directional' or 'locative' sense dimension that $a$ can capture, its role as a 'functional' preposition capturing an abstract spatial sense seems clear, in $(47-48) .^{7}$ Both sentences describe a scenario in which Mario can sit at, or go to behind, or in front, or on top (and so on) of the desk (Rizzi 1988: 500). ${ }^{8}$

Complex prepositions also display a locative/directional sense type ambiguity but seem to carry a 'lexical' sense, at the same time. Complex prepositions involve ellipsis of the ground DP (and head preposition), with the remnant spatial noun and preposition acting as a single, adverbial-like unit (e.g. di fronte in (48)). Single

7 Italian simple prepositions involve raddoppiamento sintattico ('syntactic doubling', Nespor and Napoli 1987). The fusion of $a$ and la involves the epenthetic doubling of $/ 1 /$, as the orthographic form alla suggests.

8 When $a$ heads these prepositions, it may be optional (Garzonio and Rossi 2016), and usually can also cover a "boundedness" semantic distinction (Tortora 2005, 2008). Furthermore, the other simple prepositions can occur as markers in complex prepositions that may lack a spatial sense (e.g. per colpa di 'because of'). Although not crucial to our discussion, these facts support a view of Italian simple spatial prepositions as a highly flexible category. 
coalesced items are also common (e.g. dietro 'behind' from de retro, Vincent 1999: 182), and so are items including a definite article (e.g. nel mezzo 'in the middle': Rizzi 1988; Ursini 2015). In recent work, mono-syllabic prepositions su, giù, per and tra/fra have shown to display distributional properties that bring them closer to complex prepositions. For instance, di must act as the mediating head when the ground NP is a pronoun or an indexical (e.g. tra di loro 'among them', per di qui 'through here': Franco 2018). We offer the two lists of prepositions in (49)-(50):

Mario siede/va a-lla scrivania.
Mario sits/goes at-the desk
'Mario sits at/goes to the desk.'

((=3), Rizzi 1988)

'Mario sits at/goes to the desk.'

$$
\begin{aligned}
& \text { Mario siede/va di fronte (a-lla scrivania). ((=4), Rizzi 1988) } \\
& \text { Mario sits/goes of front (at-the desk) } \\
& \text { 'Mario sits/goes in front of the desk.' }
\end{aligned}
$$

Simple prepositions: $=\{a$ 'at/to', $d a$ 'at, from', $d i$ ‘of/from/at', in 'in/into’ $\}$

Complex prepositions: $=\{\operatorname{per}(\mathrm{di})$ 'crossing, to', tra/fra (di) 'between', $s u$ (di) 'on, up, to', giù (di) 'off, down, to', attraverso (a) 'through, across', dietro a 'behind', di fronte a 'in front of', sopra (a) 'over', nel mezzo di 'in the middle of', a nord di 'North of', ...

The list in (49) includes $d a$ and $d i$ as prepositions that cover a 'functional' sense. Note that $d a$ can also cover this sense when the ground DP denotes a human referent (Luraghi 2009, 2011). A similar reasoning can be applied to di, which can combine with spatial deixis as ground DPs. For instance, the answer di là lit. 'at there' is also acceptable in a context in which Mario's location is defined with respect to a ground previously introduced in discourse. Overall, $a$, di and $d a$ retain their 'functional' sense whether they distribute as prepositions/heads, or as markers within complex prepositions. Instead, in, per, tra, su and giù seem to cover more 'lexical' senses. They capture spatial relations involving more restricted locations for a moving or lying figure. For this reason, we propose their inclusion in the list of complex prepositions (pace Rizzi 1988: 500).

A general conclusion that these data invite is that Italian represents a language in which 'functional' and 'lexical' senses seamlessly blend in prepositions, the chief spatial category. Simple prepositions can combine with spatial nouns to form one of the constituents forming complex prepositions (e.g. di and $a$ in di fronte $a$ ). In this syntactic context, their distribution is closer to that of case morphemes, thus blending 'lexical' and 'functional' senses. In isolation, simple prepositions can also cover 'lexical' senses, one example being in, and complex prepositions inherently cover 'lexical' senses as well. Overall, simple prepositions in Italian 
seem to have senses closer to the 'functional' type and complex prepositions to the 'lexical' type. Nevertheless, the boundaries between these categories appear labile in this system, since one category (prepositions) can cover both sense types.

\subsection{Interim discussion}

As our discussion suggests, the presence of a 'functional' spatial case marker in a language is tightly connected to syntactic factors of distribution. In clear languages (Lao, Fongbè, Mandarin and Tzeltal), 'functional' markers can be explicitly identified, but they can also be part of PPs in which other predicative-like categories (e.g. spatial nouns, localisers) can contribute 'lexical' senses. For blended languages, we have Māori, Estonian, Tsez and Italian to display varying degrees of morphological complexity. However, these languages converge in having multiple items covering 'functional' senses, but labile boundaries between categories and corresponding senses. In Tsez case morphemes and postpositions "agree" in the semantic type of senses they cover. In Italian, simple and complex prepositions alike can cover 'lexical' senses. In Māori and Estonian, nominal bases and postpositions seem to invariably carry these senses.

Our discussion also confirms a result of grammaticalization theory regarding spatial case markers: (co-)verbs and nouns usually evolve as categories acting as spatial case markers (cf. also Lehmann 1985: 102-103; Lestrade 2010: Ch. 4). In so doing, they can also develop increasingly 'functional' senses, and may cover a pure 'functional', abstract, spatial sense in the opportune contexts (i.e. the "AT" general concept in Levinson and Meira 2003's hierarchy). Our discussion also confirms the complementary pattern. Nouns, adverbs, localisers, nominal bases, postpositions, and other "post-ground NP" categories tend to cover more 'lexical', descriptive senses, possibly because of their status as predicative-like categories. Nevertheless, the result is that the interaction between categories forming spatial phrases can determine different solutions on how senses of increasing specificity can emerge in the lexicon of a language.

Overall, we can answer three of our four empirical questions. The first answer is that co-verbs, prepositions and structural (i.e. genitive/essive) cases invariably cover 'functional' (location) senses (Dryer 2013a). Proof is found in their distribution as "simple" items, i.e. in the absence of other morphemes possibly occurring as remnants. The second answer is that other spatial categories (e.g. verbs, case-marked nouns, postpositions, relational nouns, adverbs, localisers, prebases), whether they involve complex or simple morphological structures, invariably cover 'lexical' senses (Lestrade 2010: Ch. 6). These are the categories from which grammatical, 'functional' markers can emerge, within the lexicon. 
Crucially, these categories seem to introduce a form of reference to a third, more specific location in each underlying spatial location (e.g. 'in front', 'inside', 'behind' a ground). The 'lexical' content of these categories seems to identify these locations.

The third answer is that languages may vary with respect to how clear-cut this division of labour is. In an isolating language such as Lao, the interaction between a single 'functional' preposition and its possible 'lexical' nouns can license the formation of PPs denoting a 'lexical' relation between figure and ground. In fusive Italian, prepositions can cover 'functional' and 'lexical' sense types alike, so that prepositions can capture spatial relations with more 'lexical' (or specific) senses. Nevertheless, each grammar and lexicon of space can range over these senses in a systematic manner (Levinson and Meira 2003). For the fourth question involving a theoretical account of these categories and their grammatical and lexical relations, we formulate an answer in the next section.

\section{The analysis: Syntactic and morphological structures}

The literature on the morpho-syntactic and semantic properties of spatial categories has become voluminous. Formally inclined analyses distinguish themselves in arguing that the closely related distribution of adpositions and other spatial categories (e.g. spatial cases) underlie structural relations between these categories (e.g. LFG, Vincent 1999; HPSG, Tseng 2000; Sign Based Grammar, Sag, Boas and Kay 2012; Cartography: Cinque and Rizzi 2010). Our discussion of the data invites an analysis in which these grammatical relations are explicitly represented, thereby offering a unified but not unique representation of the spatial phrases discussed so far.

For this purpose, we offer an account presented via Lexical Syntax (Hale and Keyser 1993, 2002; Mateu 2002; Ursini and Long 2020; cf. also Emonds 1985). We make this choice for two reasons. First, the analysis of prepositions offered in this framework, known as the "P within P hypothesis" (Hale and Keyser 2002: Ch. 8), is germane to account our data. Second, the core assumptions underpinning this framework have a certain theory-neutral import, as they represent core languagespecific properties of lexical and functional items (e.g. valence, distribution) via a set of language-universal phrasal structures. Thus, we believe that our account may offer a coarse-grained account of the data. However, it can also show how language-specific categories may cover 'functional' and 'lexical' senses (or both), within the economy of spatial PPs in a given language. 
Lexical Syntax assumes that lexical or functional items belonging to languagespecific morpho-syntactic categories (e.g. prepositions, postpositions) can instantiate at least one of four abstract syntactic configurations. These configurations are based on the number of arguments that heads can combine or merge with. Since Lexical Syntax assumes a maximally binary-branching structure for phrases, it predicts that heads can have 0,1 or 2 arguments. Categories can have a flexible language-specific valence, even if they ultimately instantiate one of four resulting configurations. We present these four configurations and the phrasal structures they represent in (51):
(a) $[\mathrm{HP} \mathrm{H}]$;
(b) $\left[\mathrm{HP}_{\mathrm{P}}[\mathrm{Spec}][\mathrm{H}[\mathrm{Comp}]]\right]$;
(c) $[\mathrm{HP}[$ Spec $][\mathrm{H}[$ Pred $]]]$;
(d) $[\mathrm{HP} \mathrm{H}[$ Comp ]]

The arguments of a head are labelled as "Comp(lement)" and "Spec(ifier)". Type (a) represents a head lacking arguments, and type (d) a head taking only a complement. Type (b) represents a head taking two arguments, and type (c) a head mediating between a specifier and a predicate (i.e. a head only taking a specifier). No other types are assumed, in this framework. Hale and Keyser (2002) propose that these configurations correspond to language-universal categories (respectively nouns, verbs, adjectives and prepositions). Here we use these configurations to represent the language-specific categories attested in our sample. We then show how they can capture "shades" of the language-universal category of prepositions, in its relational and predicative "shades".

We employ four assumptions to capture the data. First, three categories act as the 'functional' elements in PPs: prepositions, co-verbs/auxiliary verbs, and genitive cases as structural cases. Second, ground DPs/NPs are invariably the complements of these PPs. Third, 'lexical' categories can become part of a PP, changing valence to merge as functional categories, and include their own morpho-syntactic structure (e.g. case suffixes). Fourth, even if in Lexical syntax different word orders are derived via movement operations, we assume that arguments of a head can be merged on either "side" (e.g. we can have [HP $_{\mathrm{HP}} \mathrm{H}$ [ Spec ]] [ Comp ]]). Although this assumption is not theoretically innocent (Haider 2013), it allows us to offer a more immediate account of the data.

Via these assumptions, we can show that the corresponding language-general configurations can be inferred from how the different categories can license 'functional' and 'lexical' configurations across languages. For instance, we can treat Mandarin prepositions as 2-place heads, but localisers as 1-place heads. In Lexical Syntax parlance, we say that Mandarin prepositions correspond to the (b) configuration, and localisers to the (d) configuration. Hence, our account differs from cartographic accounts, which assign a fixed valence to each morpheme in spatial categories. At the same time, we can avoid theoretically loaded 
commitments regarding the status of language-specific categories, e.g. that nominal-like categories (localisers, spatial nouns) may be language-specific realizations of AxPart. Once we have offered our analysis and motivated our view, we address these matters in the discussion.

Let us move to the analysis. Heads have a sub-script indicating their category (e.g. P for preposition, Co-V for co-verbs). Consider first the structures offered in (52)-(55):

Lao

a. [Co-vP $\left[\right.$ Phen $\left._{\mathrm{NP}}\right]\left[\mathrm{Co-V}\right.$, juu $_{\mathrm{Co}-\mathrm{V}}\left[\right.$ talaat $\left.\left.\left._{\mathrm{NP}}\right]\right]\right]$ 'She is at the market.'

b. $\quad{ }_{\mathrm{VP}}\left[\mathrm{Phen}_{\mathrm{NP}}\right]\left[\mathrm{V}\right.$, nang $_{\mathrm{V}}\left[\mathrm{PP}_{\mathrm{P}}[\mathrm{P}\right.$ juu [DenLocP naj $\left.]\right]\left[\right.$ huan $\left.\left.\left.\left._{\mathrm{NP}}\right]\right]\right]\right]$ 'She is/sits inside (the house).'

(53) Fongbé

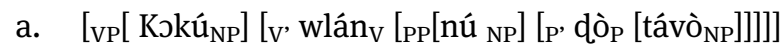

'Koku wrote something (while) at the table.'

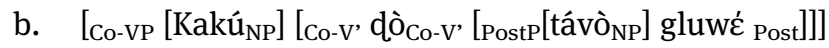
'Koku is under (the table)/bottom (of the table)'

(54) Mandarin

a. [V'P $\left[\right.$ Zhangsan $\left._{\mathrm{NP}}\right]\left[\mathrm{V}, \mathrm{zai}_{\mathrm{V}}\left[\right.\right.$ Beijing $\left.\left.\left._{\mathrm{NP}}\right]\right]\right]$ 'Zhangsan is in Beijing'

b. $\quad\left[\mathrm{VP}_{\mathrm{P}}\left[\mathrm{Zhangsan}_{\mathrm{NP}}\right]\left[\mathrm{V}_{\mathrm{V}}, \mathrm{zai}_{\mathrm{V}}\left[\mathrm{PP}_{\mathrm{PP}}\left[\operatorname{chezi}_{\mathrm{NP}}\right]\left[\mathrm{P}_{\mathrm{P}}, \operatorname{de}_{\mathrm{P}}\left[{ }_{\mathrm{NP}}\left[\operatorname{shang}_{\mathrm{Loc}}\right]-\operatorname{mian}_{\mathrm{NP}}\right]\right]\right]\right]\right]$ 'Zhangsan is in front of the table'

(55) Tzeltal

a. $\left[\mathrm{VP}_{\mathrm{P}} \mathrm{Ay}-\emptyset_{\mathrm{V}}\left[\mathrm{PP}\left[\mathrm{P}, \mathrm{ta}_{\mathrm{P}}\left[\mathrm{ajk}^{\prime} \mathrm{l}_{\mathrm{AdvP}}\right]\right]\left[\right.\right.\right.$ te limete $\left.\left.\left.{ }_{\mathrm{NP}}\right]\right]\right]$ 'The bottle is South.'

b. [VP Waxal- $\left.\emptyset_{\mathrm{V}}\left[\mathrm{PP}_{\mathrm{P}}\left[\mathrm{ta}_{\mathrm{P}}\left[\operatorname{lum}_{\mathrm{NP}}\right]\right]\left[\mathrm{p} \mathrm{in}_{\mathrm{NP}}\right]\right]\right]$ '(The) pot (is) vertically-standing on the ground'

In the Lao examples in (52b), juu acts instead as a preposition that takes a phrase headed via the denominal marker nai, which takes the ground NP huan as its complement. Thus, 'functional' juu can either occur as a co-verb or preposition, but carries a distinctive sense type. Although we do not mark the possible ellipsis sites to maintain notation readable, ellipsis can target the ground NP or the denominal phrase containing this NP (e.g. Phen juu/nang (juu) naj (huan) 'She is/sits inside (the house).' from (10)). The elided constituents license the formation of a full PP, 
but are left unpronounced (Boone 2014: Ch. 2; Merchant 2001). Note also that we use the label "NP" to avoid committing ourselves to the existence of full-fledged DPs in most of the languages under discussion. Crucially for our account, the elided constituents involve the ground NP and/or the denominal markers, the latter category covering the 'lexical' senses that can emerge in Lao PPs. Preposition/co-verb juu, instead, covers a 'functional' spatial sense, with each category clearly covering distinct senses.

Let us move to Fongbè. In (53a), we show that ground NP and direct argument (respectively távò and nú) form the arguments of dò as a 'functional' preposition describing some action being performed 'at' the table. Thus, this preposition introduces the two arguments of a di-transitive structure (Hale and Keyser 2002: Ch. 2). In (53b), this preposition becomes a 2-place head introducing "relating" figure and ground NP, with the ground NP introduced as the complement of a rightheaded postposition, gluwé 'under'. An analysis of this latter category as a relational noun or denominal element is possible, as our discussion of sense ambiguities in Fongbè has shown (cf. Section 3.1). Ground NP ellipsis becomes possible when it targets the PP including the ground, leaving the postposition carrying a 'lexical' sense as a remnant. In either type of construction, dò acts as a 'functional' preposition.

For Mandarin, (54a-b) show that the analysis of zai as a co-verb (i.e. a 2-place head) can capture its distribution with a figure and a ground NP. We also assume that de can act as a preposition-like element (whence the $\mathrm{P}$ label) in phrases involving fangweici (localisers). Note that this account trades precision for simplicity regarding de and adpositions (Zhang 2012, 2017; for recent overviews). Nevertheless, the account shows that localisers introduce a 'lexical' sense in virtue of referring to a third location conceived as "part" of a ground's space. The phrase headed via de thus establishes this 'lexical' sense, which can then restrict the 'functional' sense that zai carries, whether it merges as a co-verb or preposition. As in the case of the previous two languages, we do not explicitly mark ellipsis sites for readability. However, when ellipsis occurs localisers act as remnants carrying 'lexical' senses.

For Tzeltal, (55a) shows that ta acts as a 2-place head preposition. It takes an adverb, ajk'ol 'south-hill' as one of its arguments, the other argument being the figure NP te limete, which merges to the right of the ground NP. The verb ay-ø takes this PP as an argument and states that this relation holds (literally, it "exists"), thereby licensing the formation of a full BLC. In (55b), $t a$ also acts as a 2-place head (a P) taking the ground NP lum '(the) ground' as its complement and p'in 'the pot' as its specifier. The verb waxal describes the 'specific' spatial configuration holding between ground and pin 'pot': the latter is standing (vertically) on the former. Thus, in Tzeltal verbs and adverbs or denominal markers capture 'lexical' senses, which 
can also block the presence of a ground NP. Ta covers a purely 'functional' sense: it establishes that a relation between figure and ground holds.

Overall, clear languages show that categories with a 'functional' sense project 2-place heads (co-verbs, prepositions) that may take a ground and a figure NP as their arguments. Categories covering 'lexical' senses (denominal markers, postpositions, adverbs) can be 1-place heads (e.g. localisers in Mandarin) or 0-place heads/NPs (e.g. denominal locatives in Lao). They respectively introduce the "third" location that a figure occupies with respect to a ground (e.g. adverbials in Tzeltal), or mediate this reference by taking the ground as their complement (localisers). In either case, 'functional' and 'lexical' senses are indirectly predicted via the configurations assigned to each category.

We turn now to the blended languages by proposing the structures in (56)-(59):

(56) Māori

a. [vP [PP [P, I/kei/hei [ ope $\left.\left._{\mathrm{NP}}\right]\right]\left[\right.$ Otepoti $\left.\left.\left._{\mathrm{NP}}\right]\right] \mathrm{ia}_{\mathrm{V}}\right]$

'The group was/is/will be in Dunedin'

b. [VP $\operatorname{kei}_{\mathrm{V}}\left[\right.$ te pukapuka $\left.\mathrm{NP}_{\mathrm{NP}}\right]\left[\right.$ Pre-baseP runga $_{\text {pre-baseP }}\left[\mathrm{PP} \mathrm{i}_{\mathrm{P}}\left[\right.\right.$ te tēpu $\left.\left.\left.\mathrm{DP}_{\mathrm{DP}}\right]\right]\right]$ 'The book is on top of the table.'

(57) Estonian

a. $\left[\mathrm{VP}_{\mathrm{P}}\left[\mathrm{Mario}_{\mathrm{NP}}\right]\left[\mathrm{V}\right.\right.$, on $_{\mathrm{V}}\left[\mathrm{KP}_{\mathrm{KP}}\left[\right.\right.$ laua $\left.\left.\left.\left._{\mathrm{NP}}\right]-\mathrm{l}_{\mathrm{K}}\right]\right]\right]$

'Mario is at the desk.'

b. $\left[{ }_{v P}\left[\operatorname{Kampsun}_{\mathrm{NP}}\right]\left[\mathrm{V}_{\mathrm{V}}\right.\right.$, on $\left.\left._{\mathrm{V}}\left[\mathrm{PostP}_{\mathrm{KP}}\left[\mathrm{mantle}_{\mathrm{NP}}\right]-\emptyset_{\mathrm{K}}\right] \mathrm{al}-\mathrm{l}_{\text {Post }}\right]\right]$

'The sweater is under/below (the coat).'

(58) Tsez

a. $\left[{ }_{V P}\left[{ }_{V},\left[{ }_{K P}\left[K_{K P}\left[\right.\right.\right.\right.\right.$ yun $\left.\left.\left._{N P}\right]-\mathrm{O}_{\mathrm{K}}\right]-\chi_{\mathrm{K}}\right]\left[\left[\right.\right.$ ayi $\left.\left.\left.\left._{\mathrm{NP}}\right] \check{c ̌}^{\prime} \mathrm{iw} \chi_{\mathrm{i}}-\mathrm{x}_{\mathrm{V}}\right]\right]\right]$

'A bird is chirping on the tree.'

b. $\left[{ }_{\mathrm{VP}}\left[\mathrm{V}_{\mathrm{V}}\left[{ }_{\mathrm{PostPP}}\left[\mathrm{KP}_{\mathrm{N}}\left[\mathrm{1i}_{\mathrm{NP}}\right]-\right.\right.\right.\right.$ q'oc'o $\left.\left.\left.\left.\chi_{\mathrm{K}}\right]-\bar{a}_{\text {Post }}\right]\left[\left[\operatorname{yol}_{\mathrm{NP}}\right] \emptyset_{\mathrm{V}}\right]\right]\right]$

'Water is inside/in the interior (of the barrel).'

(59) Italian

a. $\left[\mathrm{vP}_{\mathrm{P}}\left[\right.\right.$ Mario $\left._{\mathrm{NP}}\right]\left[\mathrm{v}\right.$, siede $/ \mathrm{va}_{\mathrm{V}}\left[\mathrm{PP}\right.$ a-P $\left[\mathrm{PP} \emptyset_{\mathrm{P}}\left[\right.\right.$ la scrivania $\left.\left.\left.\left.\left.{ }_{\mathrm{DP}}\right]\right]\right]\right]\right]$

'Mario sits at/goes to the desk'

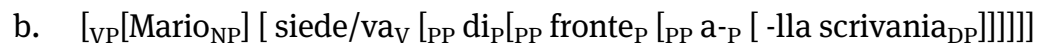
'Mario sits/goes in front of the desk' 
Consider the Māori example in (56a), first. Any of the three 'general' bases i, kei, and hei can be bases of a PP that takes a figure and ground NP (DP, in this case) as its arguments. The resulting phrase can then combine with a verb, ie, predicating the 'existence' of this relation, in a manner similar to Tzeltal. When a pre-base is present, as in (56b), one can however have the pre-base taking the PP formed via the merge of preposition and ground NP as the complement. Thus, the pre-base acts as the 'lexical' constituent that restricts the sense of the 'functional' prepositions attested in this language. The existence of several 'functional' bases also carrying 'lexical' temporal values blurs the distinction between 'functional' and 'lexical' spatial categories in this language. Furthermore, bases and pre-bases act as "parts" of a phrasal unit, which would therefore blend 'functional' and 'lexical' senses.

For Estonian, we have the emergence of two patterns involving case morphology. In the first case, an 'essive' case establishes that a 'location' relation holds between figure and ground, and forms a KP as a minimal spatial phrase (cf. (57a)). In the second case, postpositions and other categories are stacked onto this minimal phrase, which can then undergo ellipsis (cf. (57b)). Postpositions cover 'lexical' senses, but case morphemes can also capture the type of relation at stake, as the glosses “ADESSIVE”, “INESSIVE” (and so on) indirectly suggest. The less clearcut boundaries among categories forming a spatial PP in Estonian also bring a less clear-cut distinction in the sense types they cover.

The Tsez data in (58a-b) then, show similar patterns. A ground NP can merge with a sequence of stacked cases. Thus, zun-o- $\chi$ ' 'tree-on.ESS' involves an essive case capturing a 'functional' relation between tree and bird chirping on it (i.e. $-\lambda$ '), forming a complex case morpheme with - $O$-, which covers the 'lexical' sense glossed as 'on'. In (60), the postposition/adverb yot 'inside' takes a ground NP marked for case carrying a similar sense, $q$ 'oc' $o \lambda-\bar{a}$ 'inside the barrel'. The presence of postpositions licenses the possibility of eliding this case-marked ground NP. It also confirms that in Tsez spatial case morphology already blends 'functional' and 'lexical' senses, and postpositions further specify which location is at stake.

The Italian data in (59a-b) round up our discussion. For simple prepositions and their corresponding PPs, we assume that a silent sequence of heads is part of their structures (cf. (59a)). Complex prepositions minimally differ in featuring a spatial noun (AxPart, in cartographic approaches) and a simple preposition "marking” this noun as part of a complex preposition. As in the case of Tsez and its 'lexical' cases, the result is that complex prepositions carry inherently 'blended' senses (here, di fronte $a$ ). Simple prepositions can also carry such senses (e.g. in), with $a$ as a simple preposition being perhaps the only 'functional' sense preposition. 
Overall, our analysis establishes that categories conveying 'functional' senses and those carrying 'lexical' senses can involve different divisions of labour. The analysis shows that in the quartet of clear languages prepositions or other equivalent spatial case markers can cover 'functional' senses. When present, other categories can form complex spatial phrases carrying a 'lexical', or perhaps more appropriately "blended" sense. For instance, Mandarin localisers invariably restrict the sense of the $\mathrm{PP}$ they are part of, with zai carrying a 'functional' sense that emerges when the ground NP is a toponym, and localisers are optional.

The analysis also shows that their morphological interaction can lead to the emergence of complex vocabulary items, which can then carry 'lexical' senses. The quartet of blended type languages shows that this happens when languages have spatial case markers that do not permit to establish clear boundaries between categories. Thus, in Tsez structural and semantic case morphemes can cover both 'functional' and 'lexical' senses (cf. $q$ 'oc'o $\chi-\bar{a}$ 'barrel-IN.ESS'), and so can "simple" prepositions in Italian (e.g. $a$, in). The presence or absence of these elements can predict the sense attributed to a PP, via the merge of 'functional' and 'lexical' senses. When the boundary between categories is blurred because these categories carry the same valence, "'blended" senses seem to systematically emerge. When categories do not have the same valence, "clear" sense distinctions obtain.

We propose that in these cases a process of lexical and semantic conflation occurs. Building on Talmy (2000: Ch. 3)'s original proposal, Hale and Keyser (2002: Ch. 3) define morpho-syntactic conflation as the merge of two contiguous items into a single vocabulary item. Crucially, if distinct categories and their configurations conflate to form a single syntactic configuration, then their senses must also form a conflated semantic domain. The data from blended languages suggest that this prediction is on the right track. However, they hint at the possibility that conflation occurs via differing degrees of integration, hinging on which distinct spatial categories are involved in this process.

We propose to capture these facts by assuming that PPs involve a first $\mathrm{P}$ and $\mathrm{a}$ second $\mathrm{P}$ as part of their structure. These categories act as proxies for the more finegrained structure of the $\mathrm{P}$ field. We then propose that if these $\mathrm{P}$ heads are realized via language-specific categories with distinct valence, then they do not conflate. Hence, their senses also remain distinct. However, if the first and the second $\mathrm{P}$ belong to the same language-specific category and thus share their valence, then their senses can also become blended. We represent these two possibilities via the structures in (60). The superscripts " $\mathrm{X}$ " and "Y" represent variables for languagespecific categories (e.g. "co-verb”, "preposition"). The sub-scripts "funct" and "lex" represent the sense types assigned to these categories, which differ in virtue of belonging to distinct categories that nevertheless capture spatial senses: 

a. $\quad\left[\mathrm{PP}\left[\mathrm{NP}_{\text {figure }}\right]\left[\mathrm{P}_{\text {funct }}^{\mathrm{X}}\left[\mathrm{PP}\left[\mathrm{NP}_{\text {ground }}\right] \mathrm{P}_{\text {lex }}^{\mathrm{Y}}\right]\right]\right]$
b. $\quad\left[\mathrm{PP}\left[\mathrm{P}, \mathrm{P}_{\text {funct }}^{\mathrm{X}}\left[\mathrm{PP} \mathrm{P}_{\text {lex }}^{\mathrm{Y}}\right]\right]\left[\mathrm{NP}_{\text {ground }}\right]\right]$
c. $\quad\left[{ }_{P P} P_{\text {sense }=\{\text { funct,lex }\}}^{X}\left[{ }_{P P} P_{\text {sense }=\{\text { funct,lex }\}}^{X}\left[\mathrm{NP}_{\text {ground }}\right]\right]\right]$

The structure in (60a) captures in a compact manner most of the cases observed in clear languages, even though it abstracts away from word order details. The superscripts $X$ and $Y$ (indirectly) represent the fact that co-verbs (e.g. Lao, Mandarin) and prepositions (e.g. Fongbè) in these languages are distinct categories from the categories referring to specific locations (e.g. relational nouns in Tzeltal, spatial nouns in Fongbè, localisers in Mandarin). The structure captures cases in which $\mathrm{P}^{\mathrm{X}}$ corresponds to a 2-place head taking figure and ground NP as its arguments, but with the ground NP being introduced via $\mathrm{P}^{\mathrm{y}}$ (cf. the Fongbè structures in (53)). In these cases, one category seems to relate figure and ground when no other more restricted location is mentioned, and thus carries a 2-place configuration. The other category may select a third location when present, in a sense describing it as a "part" or "axis" of the ground.

The structure in $(60 \mathrm{~b})$ shows a variant involving ground $\mathrm{NP}$ and $\mathrm{P}^{\mathrm{Y}}$ categories as 0-place heads (i.e. phrases/arguments) of the 'functional' category. This structure is found in Lao (cf. (52b)), and Tzeltal (cf. (55)). In these cases, $\mathrm{P}^{\mathrm{X}}$ categories maintain their relational configuration but mediate a relation between ground and third location, within another category (e.g. verbs in Lao). Alternatively, these categories can mediate a relation between figure and third location, the ground possibly becoming an implicit argument as in the case of Tzeltal. In each of these cases, the $\mathrm{P}^{\mathrm{X}}$ categories carry a funct sense, possibly corresponding to a 2-place spatial relation. The $\mathrm{P}^{\mathrm{Y}}$ categories instead carry a lex sense, i.e. a sense that refers to the third location by identifying its core properties (e.g. being "the front location" of the ground: Matushansky and Zwarts 2019, a.o.).

The structure in (60c) shows that languages in which the two P items have the same valence and can be realized via the same categories lack this semantic distinction (e.g. bases in Māori, prepositions in Italian, case morphemes and postpositions in Estonian and Tsez). The two senses 'functional' and 'lexical' are conflated/blended into a single sense, represented as sense $=\{$ funct,lex $\}$. No valence difference entails no sense (domain) difference. In these languages, $\mathrm{P}^{\mathrm{X}}$ categories do not mediate between figure and ground, but seem to introduce grounds as arguments of verbs, and the spatial relations (and locations) depending on these grounds. Relational senses thus seem to also incorporate a lexical component specifying which location the figure occupies (e.g. Italian di fronte $a$ 'in front of').

We thus show that although our use of Lexical Syntax offers a coarse-grained account of spatial case markers across our language sample, it can nevertheless 
predict their semantic behaviour. In our sample, blended languages seem to determine degrees of conflation among "spatial” categories. If in a language different projections "blend" into the single "preposition" category, then "functional' and 'lexical' senses will also blend into a single semantic domain. If in a language different projections form distinct or "clear" domains (e.g. prepositions and localisers in Mandarin), then 'functional' and 'lexical' senses will be distinct.

Via our account we can also capture the fact that clear languages introduce direct reference to a third location via one of the two categories. Instead, blended languages conflate an "abstract" spatial relation and reference a third location. For instance, in Mandarin prepositions correspond to the $\mathrm{P}^{\mathrm{X}}$ category and are 2-place heads with a 'functional' sense: they "only" relate figure and ground. Localisers correspond to the $\mathrm{P}^{\mathrm{Y}}$ category and are either 1-place (e.g. qian) or 0-place heads (e.g. qian-mian) with a 'lexical' sense: they refer to the third location (here, the 'front' location). In Italian, a preposition such as di fronte refers to a 'front' location, but it does by being part of a complex preposition as a sequence of 1-place heads. Thus, even if all languages can capture spatial relations of different degrees of "abstraction", these relations mirror in structure the syntactic properties of their spatial categories. With this point in mind, we turn to the discussion.

\section{Discussion}

In this section, we compare our account with previous proposals. We first focus on generative accounts, and then conclude with a compact comparison with typological works. Because of space limits, our discussion will be accurate but limited to key representative works.

The first point of comparison involves our account of spatial categories and their configurations with cartographic approaches. As discussed in Section 2, cartographic proposals treat prepositions and other spatial case morphemes as sequences of functional heads that can however "embed" lexical content. Labels display a strong degree of iconicity, for they aim to capture the content that may be associated to each head (e.g. AxPart for terms such as English front). Works differ regarding the number and "position" of these heads. Thus, here we concentrate on sketching points of convergence between our proposal and what we believe to be three key proposals: Svenonius (2010), den Dikken (2010), and Noonan (2010). Other proposals anticipate (e.g. Asbury 2008; Svenonius 2006) or partly differ from these proposals (e.g. Pantcheva 2011; Terzi 2010), but maintain their core assumptions. Thus, we assume that our arguments may extend to them, too.

In Svenonius (2010: 140), it is suggested that English prepositions involve (at least) the sequence of heads presented in (60a). The category $p$ ("small p") is 
assumed to establish a relation between figure and ground, but does not add other content: though not explicitly stated, it should be a 2-place head. The other heads are represented as 1-place heads entering head-complement relations via their maximal projections. Deix(is) and Deg(ree) are heads introducing deictic and degree content. AxPart, as mentioned in Section 2.1, denote the third location(s) that the figure occupies. In den Dikken (2010: 122), the categories Place and Path are treated as loci of insertion for 'lexical' content in Dutch prepositions. We restrict the sequence of functional heads in (60b) to the Place layer, and show that reiterated 'functional' sequences can then stack onto a "core” ground DP. In Noonan (2010: 187), a proposal is made for German and English prepositions that follows the same philosophy, but uses different labels. We also restrict this sequence to the "Place" layer (cf. (60c)): ${ }^{9}$

$$
\begin{aligned}
& \text { a. p-Deg-Deix-Place-Axpart-Kase-DP } \\
& \text { b. } \mathrm{C}_{\text {Place }}-\text { Deg }_{\text {Place }}-\text { Place-Ploc-DP } \\
& \text { c. } \mathrm{P}_{\text {loc }}-\mathrm{P}_{\text {place }}-\text { Mode }_{\text {place }}-\text { Place-DP }
\end{aligned}
$$

We believe that there are two clear points of convergence with our proposal that permit us to offer an explicit comparison, starting from Svenonius (2010). First, the category $p$ and the $\mathrm{P}^{\mathrm{X}}$ categories corresponding to 2-place heads (e.g. co-verbs in Lao and Fongbè, prepositions in Mandarin and Tzeltal) seem equivalent in their 'functional' sense. They all seem to relate figure and ground, and to carry no other 'function' in a sentence. Second, AxPart, and $\mathrm{P}^{\mathrm{Y}}$ categories referring to specific locations (e.g. postpositions in Fongbè, Estonian, Tsez, prepositions in Italian) seem to be similar, though not entirely equivalent. If instead we compare our proposal with den Dikken (2010)'s, a counterpart of $\mathrm{P}^{\mathrm{X}}$ may be the $\mathrm{C}$ head acting as the landing/merging site for the figure NP, and Place the locus for more 'lexical' elements. In Noonan (2010), similar heads seem $\mathrm{P}_{\text {loc }}$ and Mod $_{\text {Place, }}$, since they are assumed to respectively capture the "relational" nature of prepositions and their "configurational" content.

Crucially, our proposal differs from these proposals because we treat $\mathrm{P}^{\mathrm{Y}}$ categories (e.g. relational nouns, localisers) as arguments of other Ps (i.e. as 0-place heads), in clear languages. We also do not differentiate between categories that might realise AxPart heads and categories that might realise RelN, the category of (spatial) relational nouns fully discussed in Svenonius (2006). Nevertheless, we

\footnotetext{
9 These three cartographic works investigate the structure of the "Path" layer and its possible directional senses, but here we focus on locative senses, whether they may be 'functional' or 'locative'. Our generalizations on these senses seem to be extendable to categories carrying "path" senses (e.g. Mandarin and Fongbè prepositions), but they would require a further study to be confirmed. We thus leave this matter aside for further investigations.
} 
acknowledge that Svenonius (2010)'s proposal may model how certain "parts" of the P field can have clearly 'functional' or 'lexical' senses. The proposals in den Dikken (2010) and Noonan (2010), instead, assume that $\mathrm{P}_{\text {loc }}$ is a head including the 'lexical' (Path or Place) content of a preposition, and the subsequent heads add 'functional' content. Though sense distinctions are derived from structural distinctions, these works seem to assume that the homogeneous argument structure of functional sequences might lead to forms of conflation patterns across prepositions.

For these reasons, we believe that these three proposals leave open the question of how these structures can be extended to our sample of clear languages. Perhaps an integration of the $p$ head proposal within the other two proposals would result in an overarching theory that could also capture our data. However, we conjecture that more work would be needed to handle the 'functional'/'lexical' divide and valence matters in clear languages. The cartographic assumption that 'functional' and 'lexical' spatial categories always blend into rich sequences of heads may require an alternative formulation. Our proposal fares better on these data, if only because it takes a more flexible view on categories forming the " $P$ field", and their configuration/valence.

The second point of comparison involves our approach to conflation with two other models of vocabulary item insertion. We believe that two such proposals are relevant to this discussion: Acedo-Matellán (2016)'s analysis of verbs and prepositions capturing “transitions”, and Bye and Svenonius (2012)'s theory of spans. Theories such as Distributed Morphology (Embick 2010; and references therein) offer extensive proposals on equivalent data. Perhaps precisely for this reason, they would require us to offer too long a discussion to show how they could handle our data. Similarly, Caha (2009), and Pantcheva (2011), among others, develop accounts of possible conflation/fusion patterns in spatial categories based on the superset principle from Nanosyntax: lexical insertion may target clusters of related heads. These theories, however, also offer very fine-grained analyses that would require extensive discussion, especially once we look at the data from clear languages. We thus focus on spans and transitions while acknowledging that our discussion is rather limited in scope.

Acedo-Matellán (2016) offers an analysis of Latin verbs and prepositions which aims to reconstruct the satellite- vs. verb-framed typological distinction from Talmy (2000) in a neo-constructionist perspective. Central to our concerns is the assumption, borrowed from Distributed Morphology, that a-categorial roots are the elements carrying encyclopaedic or 'lexical' content in verbs and prepositions. Heads combining with roots to form categories are instead inherently 'functional', and determine the morpho-syntactic and lexical structure of vocabulary items and the sentences they form. Thus, in this proposal 'functional' and 'lexical' categories 
start as clearly distinct items, but they may become blended in Latin and other languages.

One such case is Latin in 'in', which involves the adjunction of a root capturing a "specific" location (e.g. IN for inclusion) with a Place head establishing a relation between figure and ground. The "abstract” or 'functional' preposition ad 'at/to' is instead claimed to involve an empty root item that determines the abstract, relational content of the preposition (Acedo-Matellán 2016: 78-84). A Path head can then determine whether a PlaceP denotes a location as the "goal" "location", "source" (and so on) of an event of motion or a state. More in general, root adjunction and head movement are assumed to trigger conflation ("fusion", in Distributed Morphology) patterns. Once the work addresses data and languages beyond Latin, it shows that such assumptions can derive the continuum of patterns between the satellite- and verb-framed poles of Talmy (2000)'s original typology.

Bye and Svenonius (2012)'s proposal focuses on "spans", or sequences of heads that enter in head- complement relations via their maximal projections. This work proposes that there is a strict distinction between syntactic derivations and lexical insertion. Lexical insertion occurs after syntactic derivations, and can target sequences of maximal projections (spans) if it matches the features that these projections carry. Thus, the framework can capture a wealth of phenomena such as portmanteau words and non-concatenative morphology. Closer to our topic, it can capture how spans qua sequences of heads may correspond to single prepositions (e.g. at), or prepositions forming single lexical units (e.g. in front of ). For languages such as Mandarin, the proposal may capture how distinct categories can form discontinuous spans (e.g. preposition zai and localiser qian in zai chezi qian 'in front of the desk').

As our compact discussion suggests, these proposals seem to lend themselves to an account of blended languages and their spatial categories. Although AcedoMatellán (2016) does not tackle more complex prepositions akin to in front of, its roots adjoined to Place heads seem equivalent to our $\mathrm{P}^{\mathrm{Y}}$ categories, and Place heads seem equivalent to $\mathrm{P}^{\mathrm{X}}$ categories. A possibility is that this theory could be extended to clear languages by assuming that roots in those languages may be realised as bare NP-like arguments in structures (e.g. spatial nouns/NPs in Lao and Tzeltal). Similarly, Bye and Svenonius (2012)'s proposal could certainly model spatial categories in clear languages as discontinuous categories. This proposal does not fully address the potential differences between 'lexical' and 'functional' heads, but the formal requirements for the formation of spans might be used to derive the relevant categorial distinctions. For instance, Lao's prepositions/coverbs seem not to form a span with denominal locatives, for this latter category is one of the co-verb's arguments. Italian prepositions, instead, seem a perfect example of a "P span" as a sequence of heads. 
We believe that working out the details of how these proposals may be extended to cover these data ultimately fall outside the scope of our proposal. We nevertheless observe that a degree of convergence between our proposals and other extant proposals on the possible conflation patterns of spatial categories is a welcome result. Before we move to the conclusions, however, we wish to offer a final observation on how our account is also consistent with the typological accounts from Section 2. We do so by repeating in (61) the lexical and syntactic clines first introduced in (3)-(4), and analysing how they are related to our findings:

$$
\begin{array}{ll}
\text { a. } & \mathrm{AT}_{4}, \mathrm{ON}-\mathrm{TOP}, \mathrm{ATTACHED}, \mathrm{NEAR} . . \leqslant \mathrm{INSIDE}, \mathrm{IN}, \mathrm{ON}_{1}, \mathrm{AT}_{3} \preccurlyeq \mathrm{IN}_{1}, \\
& \mathrm{AT}_{2} \preccurlyeq \mathrm{AT} \\
\text { b. } & \text { Relational noun } \preccurlyeq \text { Particle, } \\
& \text { Adverb } \preccurlyeq \text { Postposition } \preccurlyeq \text { Preposition } \preccurlyeq \text { Agglutinative case } \preccurlyeq \text { Fusive case }
\end{array}
$$

As our discussion suggests, the 'functional' concept AT is realized in clear languages via prepositions/co-verbs, such as Lao juu, Mandarin zai, Fongbè dò, and Tzeltal ta. In blended languages, this division is less clear-cut. In Māori, AT is covered via $i$, hei and kei as 'functional' bases with an added temporal dimension. In Estonian and Tsez, different essive cases can cover a general sense in the opportune context, and in Italian simple preposition a may do so in basic BLCs. Our account can be conceived as capturing these possible relations between the two clines, and thus extends typological observations regarding the 'functional/ lexical' sense distinction in a subtle manner. Lehmann (1985: 103-104) and subsequent works propose that sense specificity and morphological complexity seem to go hand in hand. The more morphologically complex spatial case markers become, the more specific, lexically rich their senses are. Our novel results seem to confirm this view, by showing that different categories across languages can be involved in these patterns, in subtle manners. With this point in mind, we turn to the conclusions.

\section{Conclusions}

The goal of this paper has been to solve four problems regarding the nature of 'functional' and 'lexical' senses in spatial case markers. A first problem has been to assess the categories that cover these sense types: a second, the mechanisms deriving these categories; a third, the relation between categories and sense types. We have also addressed a fourth problem: offering a unified account of the solutions to these problems. We thus have shown that language can partition the domain of spatial case markers (the P field of cartographic analyses) in various 
manners. As a result, languages can also involve different partitions of senses. Clear type languages have categories carrying distinct senses to denote relations between figure, ground and possibly a third location. Blended languages mostly lack this distinction. Therefore, we have shown that languages that "conflate" spatial categories and their senses seem to also conflate this sense distinction in a systematic manner.

Overall, in our account these levels can be conceived as the result of the systematic interaction (i.e. the grammar) of grammatical and lexical (spatial) items to form PPs. By studying the grammar and the lexicon of this sub-domain of language, we can shed light on how the wealth of different linguistic patterns can be reduced to a set of near-universal categories and rules. In so doing, we can offer a first account of the relation between 'functional' and 'lexical' spatial case markers in languages. However, it does not address other topics mentioned during our discussion; those must wait for future research.

\section{Abbreviations}

$\begin{array}{ll}\text { ABS } & \text { absolutive } \\ \text { ADE } & \text { adessive } \\ \text { ALL } & \text { allative } \\ \text { CL } & \text { clitic } \\ \text { CONT.ESS } & \text { contessive } \\ \text { DEF } & \text { definite marker } \\ \text { DIR } & \text { directional marker } \\ \text { ERG } & \text { ergative } \\ \text { ESS } & \text { essive } \\ \text { EXIST } & \text { existential predicate } \\ \text { FUT } & \text { future } \\ \text { GEN } & \text { genitive } \\ \text { IMPER } & \text { imperfective } \\ \text { IN.ESS } & \text { inessive } \\ \text { LAT } & \text { lative } \\ \text { LOC } & \text { locative } \\ \text { NOM } & \text { nominative } \\ \text { OBL } & \text { oblique } \\ \text { POSS } & \text { possessive } \\ \text { P } & \text { Preposition } \\ \text { PLU } & \text { plural } \\ \text { PRS } & \text { present } \\ \text { SUB.ESS } & \text { subessive } \\ \text { SUPER.ESS } & \text { superessive } \\ \text { 3RDSG } & \text { Third singular person } \\ & \end{array}$




\section{References}

Abondolo, David. 1998. Introduction. In David Abondolo (ed.), The Uralic languages, 3-30. London: Routledge.

Acedo-Matellán, Víctor. 2016. The Morphosyntax of transitions: A case study in Latin and other languages. Oxford: Oxford University Press.

Aikenvhald, Alexandra \& Richard M. W. Dixon (eds.). 2006. Serial verb constructions: A crosslinguistic typology. Oxford: Oxford University Press.

Alekseev, Mikhail E. \& Ramazan N. Rajabov. 1991. Tsez language. In Michael Job (ed.), Indigenous languages of the Caucasus, vol. 3, 70-101. Ann Arbor: Caravan Books.

Alekseev, Mikhail E. \& Ramazan N. Rajabov. 1993. Prerequisites to the formation of Tsez writing system. In George Hewitt (ed.), Caucasian perspectives, 372-376. Munich: Lincom Europa.

Asbury, Anna. 2008. The Morphosyntax of case and adpositions. Utrecht: University of Utrecht doctoral dissertation.

Aurnague, Michel \& Laurie Vieu. 2015. Function versus regions in spatial language: A fundamental distinction. In Astésano Claude \& Melissa Jucla (eds.), Neuropsycholinguistic perspectives on language cognition. Essays in honour of Jean-Luc Nespoulous, 31-45. London/New York: Psychology Press.

Bauer, Winifred. 1993. Maori. London and New York: Routledge.

Bauer, Winifred. 1997. The reed reference grammar of Maori. Auckland: Reed.

Becquelin, Alain. 1997. Parlons Tzeltal: Une langue Maya du Mexique. Paris: L'Harmattan.

Bennett, David. 1975. Spatial and temporal uses of English prepositions: An essay in stratificational semantics. Indiana: Indiana University doctoral dissertation.

Berlin, Brent \& Paul Kay. 1969. Basic Color Terms: Their Universality and Evolution. Berkeley: University of California Press.

Biggs, Bruce. 1961. The structure of New Zealand Māori. Anthropological Linguistics 3(3). 1-54.

Biggs, Bruce. 1969. Let's Learn Māori: A Guide to the Study of Māori Language. Auckland: Auckland University Press.

Blake, Barry J. 2001. Case, 3rd edn. Cambridge: Cambridge University Press.

Blevins, James P. 2005. Word-based declensions in Estonian. In Geert Booij \& Jaap van Marle (eds.), Yearbook of morphology 2005, 1-25. Berlin: Mouton De Gruyter.

Bohnemeyer, Jurgen. 2012. A vector space semantics for reference frames in Yucatec. In Elizabeth Bogal-Allbritten (ed.), Proceedings of the Sixth Meeting on the semantics of underrepresented languages in the Americas (SULA 6) and SULA-Bar, 15-34. Amherst: GLSA Publications.

Boone, E. 2014. The syntax and licensing of gapping and fragments. Leiden University Dissertation.

Bowerman, Melissa \& Sonia Choi. 2001. Shaping meanings for language: Universal and languagespecific in the acquisition of spatial semantic categories. In Melissa Bowerman \& Stephen C. Levinson (eds.), Language acquisition and conceptual development, 473-511. Cambridge: Cambridge University Press.

Bowerman, Melissa \& Edward Pederson. 1992. Cross-linguistic studies of spatial semantic organization. In Annual Report of the Max Planck Institute for Psycholinguistics, 53-56. Nimejgen: Max Planck Institute Press.

Brown, Penelope. 1994. The INs and ONs of Tzeltal locative expressions: The semantics of static descriptions of location. Linguistics 32(5). 743-90. 
Brown, Penelope. 2006. A sketch of the grammar of space in Tzeltal. In Stephen C. Levinson \& David P. Wilkins (eds.), Grammars of space: Explorations in cognitive diversity, 230-272. Cambridge: Cambridge University Press.

Brugman, Claudia. 1988. The story of over: Polysemy, semantics, and the structure of the lexicon. New York: Garland.

Burenhult, Nicholas \& Stephen C. Levinson. 2008. Language and landscape: A cross-linguistic perspective. Language Sciences 30(2/3). 135-150.

Bybee, Joan L. 1985. Morphology: A study of the relation between meaning and form. Amsterdam: John Benjamins.

Bye, Patrik \& Peter Svenonius. 2012. Non-concatenative morphology as epiphenomenon. In Jochen Trommer (ed.), The morphology and phonology of exponence, 427-495. 0xford: Oxford University Press.

Caha, Pavel. 2009. The nanosyntax of case. Trømso: Trømso University doctoral dissertation.

Canac-Marquis, Mea. 1986. Sur le statut categorique et syntactique de P en Fon. In Claire Lefevbre, \& Jonathan Kaye (eds.), Études syntactiques, morphologiques et phonologiques. Research prepared for SSHRCC, FCAR and PAFAC on the project Recherche de Haiti-Fon, 41-53. Université du Quebec à Montréal.

Capo, Herman B. C. 1979. Notes on language differentiation: Lessons from a Gbe dialect survey. Anthropological Linguistics 21(4). 419-442.

Chao, Yuen Ren. 1968. A grammar of spoken Chinese. Berkeley: University of California Press.

Cinque, Guglielmo \& Luigi Rizzi. (eds.). 2010. Mapping spatial P: The cartography of syntactic structures, vol. 6. Oxford: Oxford University Press.

Comrie, Bernhard. 1988. General features of the uralic languages. In Denis Sinor (ed.), The Uralic languages, 451-477. Leiden: Brill.

Comrie, Bernard. 1999. Spatial cases in Daghestanian languages. Sprachtypologie und Universalienforschung 52(2). 108-117.

Comrie, Bernard \& Maria Polinsky. 1998. The great Daghestanian case hoax. In Anna Siewierska \& Jae Jung Song (eds.), Case, typology and grammar: In honor of Barry J. Blake, 95-114. Amsterdam: John Benjamins.

Cook, Ken. 2002. The case markings of Hawaiian locative nouns and placenames. In Giovanni Bennardo (ed.), Representing space in oceania, 91-106. Canberra: Pacific Linguistics.

Coventry, Kenny R. \& Stephen C. Garrod. 2004. Saying, seeing and acting: The psychological semantics of spatial prepositions. East Sussex, England: Psychology Press.

Cresswell, Maxwell J. 1978. Prepositions and points of view. Linguistics and Philosophy 2(1). 1-41.

Croft, William. 2003. Typology and universals, 2nd edn. Cambridge: Cambridge University Press.

Cysouw, Michael \& Diana Forker. 2009. Reconstruction of morphosyntactic function: Nonspatial use of spatial case marking in Tsezic. Language 85(5). 588-617.

DeLancey, Scott. 2005. Adpositions as a non-universal category. In Zygmunt Frajzyngier \& Adam Hodges (eds.), Linguistic diversity and language theories, 185-202. Amsterdam: John Benjamins.

Djamouri, Redouane, Waltraud Paul \& John Whitman. 2013. Postpositions vs. prepositions in Mandarin Chinese: The articulation of disharmony. In Theresa Biberauer \& Michelle Sheehan (eds.), Theoretical approaches to disharmonic word order, 69-101. Oxford: Oxford University Press.

Dikken, Marcel den. 2010. On the functional structure of locative and directional PPs. In Guglielmo Cinque \& Luigi Rizzi. (eds.), Mapping spatial P: The cartography of syntactic structures, vol. 6, 74-126. Oxford: Oxford University Press. 
Dryer, S. Matthew. 2013a. Order of adposition and noun phrase. In Matthew Dryer \& Martin Haspelmath (eds.), The world atlas of language structures online. Leipzig: Max Planck Institute for Evolutionary Anthropology. Available online at http://wals.info/chapter/85, Accessed on 23 October 2017).

Dryer, Matthew. 2013b. Relationship between the order of object and verb and the order of adposition and noun phrase. In Matthew Dryer \& Martin Haspelmath (eds.), The world atlas of language structures online. Leipzig: Max Planck Institute for Evolutionary Anthropology. Available online at http://wals.info/chapter/95, Accessed on 23 October 2017).

Embick, David. 2010. Localism versus globalism in morphology and phonology. Cambridge, MA: MIT Press.

Emonds, John. 1985. A unified theory of syntactic categories. Dordrecht: Foris Publications.

Enfield, Nicholas J. 2004. Nominal classification in Lao: A sketch. Sprachtypologie und Universalienforschung 57(2/3). 117-143.

Enfield, Nicholas J. 2006. Lao body part terms. Language Sciences 28 (2-3). 181-200.

Enfield, Nicholas J. 2007. A grammar of Lao. Berlin: Mouton de Gruyter.

Enfield, Nicholas J. 2010. Questions and responses in Lao. Journal of Pragmatics 42(12). 2649-2665.

Enfield, Nicholas, Asifa Majid \& Marie van Staden. 2006. Cross-linguistic categorization of the body: Introduction. Language Sciences 28 (2-3). 137-147.

Erelt, Mati (ed.). 2003. Estonian language. Tallinn: Estonian Academy Publishers.

Ernst, Thomas. 1988. Chinese postpositions? -Again. Journal of Chinese Linguistics 16(2). 219-245.

Evans, Vyvyan. 2009. Semantic representation in LCCM theory. In Vyvyan Evans \& Stefane Pourcel (eds.), New directions in cognitive linguistics, 50-80. Amsterdam: John Benjamins.

Evans, Vyvyan \& Andrea Tyler. 2004. Spatial experience, lexical structure and motivation: The case of in. In Gunther Radden \& Klaus-Uwe Panther (eds.),Studies in linguistic motivation, 157-192. Berlin and New York: Mouton de Gruyter.

Feist, Michelle. 2006. Where it's at. Paper presented at the 7th Conference of the High Desert Linguistics Society, Albuquerque, NM.

Feist, Michelle I. 2008. Space between languages. Cognitive Science 32(7). 1177-1199.

Folli, Raffaella. 2002. Constructing telicity in English and Italian. Oxford. University of Oxford doctoral dissertation.

Folli, Raffaella. 2008. Complex PPs in Italian. In Anna Asbury, Jacub Dotlačil, Berit Gehrke, Øystein Nilsen \& Rick Nouwen (eds.), The syntax and semantics of spatial P, 197-220. Amsterdam: John Benjamins.

Forker, Diana. 2010. Variation in stem formation in Tsezic languages. Suvremena Lingvistika 69(2). 1-19.

Franco, Ludovico. 2018. (Im)proper prepositions in (Old and Modern) Italian. Manuscript, University of Florence.

Garzonio, Jacopo \& Silvia Rossi. 2016. Case in Italian complex PPs. In Ernestina Carrilho, Alexandra Fiéis, Maria Lobo \& Sandra Pereira (eds.), Romance languages and linguistic theory 10, Selected papers from 'Going Romance', vol. 28, 121-137. Amsterdam, Philadelphia: John Benjamins.

Gehrke, Berit. 2008. Ps in motion: On the semantics and syntax of $P$ elements and motion events. Utrecht: Utrecht University doctoral dissertation.

Georgakopoulos, Thanasis \& Stéphane Polis. 2018. The semantic map Model State of the art and future avenues for linguistic research. Language and Linguistics Compass 12(9). 1-33. 
Grimes, Barbara F. (ed.). 1996. Ethnologue: Languages of the world, 13th edn. Dallas, TX: Summer Institute of Linguistics.

Habicht, Külli. 2001. On the genesis and loss of the adposition rinnas ('abreast, beside') in Literary Estonian. In Ilona Tragel (ed.), Papers in Estonian cognitive linguistics, 71-89. Tartu: Tartu University Press.

Hagège, Claude. 2010. Adpositions. Oxford: Oxford University Press.

Haider, Hubert. 2013. Head directionality-in syntax and morphology. In Fábregas Antonio, Jaume Mateu \& Mike Putnam (eds.), The handbook of parameters, 68-83. New York: Bloombury Academic.

Hale, Ken \& Samuel J. Keyser. 1993. On argument structure and the lexical expression of syntactic relations. The view from building 20: Essays in linguistics in honor of Sylvain Bromberger, 53-111. Cambridge, MA: MIT Press.

Hale, Ken \& Samuel J. Keyser. 2002. Prolegomena to a theory of argument structure. Cambridge, MA: MIT Press.

Harlow, Ray. 2001. A Maori reference grammar. Auckland: Pearson education New Zealand. Harlow, Ray. 2007. Maori: A linguistic introduction. Cambridge: Cambridge University Press. Haselbach, Boris. 2017. Ps at the interfaces: On the syntax, semantics and morphology of spatial prepositions in German. University of Stuttgart dissertation.

Haspelmath, Martin. 1997. From space to time: Temporal adverbials in the world's languages. Newcastle: Lincom Europa.

Haviland, John B. 1992. Seated and settled Tzotzil verbs of the body. Zeit. Phonetik, Sprachwissenschaft und Kommunikationsforschung 45(2). 543-561.

Heine, Bernd. 2003. Grammaticalization. In Lavis Janda \& Emund Joseph (eds.), The handbook of historical linguistics, 575-601. Oxford: Blackwell.

Heine, Bernd \& Tania Kuteva 2007. The genesis of grammar. A reconstruction. Studies in the evolution of language. Oxford/New York: Oxford University Press.

Heine, Bernd, Ulrike Claudi, Frederike Hünnemeyer 1991. Grammaticalization: A conceptual framework. Chicago/London: University of Chicago Press.

Herskovits, Annette. 1986. Language and spatial cognition: An interdisciplinary study of the prepositions in English. Cambridge: Cambridge University Press.

Hiietam, Katrin. 2005. Case marking in Estonian grammatical relations. The University of Leeds Working Papers in Linguistics and Phonetics 10. 1-18.

Hopper, Paul J., Elizabeth Closs Traugott. 2003. Grammaticalization, 2nd edn. Cambridge: Cambridge University Press.

Huang, James. 2009. Lexical decomposition, silent categories, and the localizer phrase. Yuyanxue Luncong 39(1). 86-122.

Huddleston, Rodney \& Geoffrey K. Pullum. 2002. The Cambridge grammar of the English language. Cambridge: Cambridge University Press.

Jackendoff, Ray. 1983. Semantics and cognition. Cambridge, MA: The MIT Press.

Jackendoff, Ray. 1990. Semantic structures. Cambridge, MA: The MIT Press.

Jürine, Anne. 2015. The development of complex postpositions in Estonian: A case of grammaticalization via lexicalization. Tartu: University of Tartu doctoral dissertation.

Karttunen, Lauri. 1976. Discourse referents. In James D. McCawley (ed.), Syntax and semantics, vol. 7, 363-386. New York: Academic Press.

Kerr, Allen. 1994. Lao-English dictionary. London: White Lotus.

Kibrik, Andrej. 2013. Reference in discourse. Oxford: Oxford University Press. 
Koopman, Hilda. 2000. Prepositions, postpositions, circumpositions and particles: The structure of Dutch PPs. In Hilda Koopman (ed.), The syntax of specifiers and heads, 204-260. London: Routledge.

König, Christa. 2011. The grammaticalization of adpositions and case marking. In Bernd Heine \& Heiko Narrog (eds.). The Oxford handbook of grammaticalization, nn. pp. Oxford: Oxford University Press.

Kracht, Marcus. 2002. On the semantics of locatives. Linguistics and Philosophy 25(1). 57-132.

Lakoff, George. 1987. Women, fire, and dangerous things: What categories reveal about the mind. Chicago: University of Chicago Press.

Ledgeway, Adam. 2016. Italian, Tuscan, and Corsican. In Adam Ledgeway \& Martin Maiden (eds.), The Oxford guide to the romance languages, 596-610. Oxford: Oxford University Press.

Lefebvre, Claire. 1989. Complex prepositional phrases: Another case of serialisation. In Claire Lefevbre (ed.), Études syntactiques, morphologiques et phonologiques. Research prepared for SSHRCC, FCAR and PAFAC on the project Recherche de Haiti-Fon, 278-293. Montreal: Université du Quebec à Montréal.

Lefebvre, Claire. 1990. Establishing a category P in Fon. The Journal of Western African Languages 21(1). 21-35.

Lefebvre, Claire \& Anne-Marie Brusseau. 2002. A grammar of Fongbè. Berlin: Mouton De Gruyter. Lehmann, Christian. 1985. Thoughts on grammaticalization. Munich: Lincom Europa.

Lestrade, Sander. 2010. The space of case, PhD thesis, Radboud University Nijmegen.

Levinson, Stephen C. 1994. Vision, shape, and linguistic description: Tzeltal body-part terminology and object description. Linguistics 32(4-5). 791-856.

Levinson, Stephen C. 1996. Frames of reference and Molyneux's question: Crosslinguistic evidence. Language and Space 109(1). 169-210.

Levinson, Stephen C. 2003. Space in language and cognition: Explorations in cognitive diversity, vol. 5. Cambridge: Cambridge University Press.

Levinson, Stephen, Sergio Meira \& the Language and Cognition Group. 2003. Natural concepts in the spatial topological domain - adpositional meanings in crosslinguistic perspective: An exercise in semantic typology. Language 79(3). 485-516.

Levinson, Stephen C. \& Dan P. Wilkins (eds.). 2006. Grammars of space: Explorations in cognitive diversity. Cambridge: Cambridge University Press.

Li, Charles \& Sandra Thompson. 1981. Mandarin Chinese: A functional reference grammar. Berkeley: University of California Press.

Libert, Alan R. 2006. Ambipositions. Munich: Lincom Europa.

Libert, Alan R. 2013. Adpositions and other parts of speech. Frankfurt am Main: Peter Lang.

Liu, Feng-hsi. 1998. A clitic analysis of locative particles. Journal of Chinese Linguistics 26(1). 48-70.

Luraghi, Silvia. 2009. A model for representing polysemy: The Italian preposition da. In Jacques François, Éric Gilbert \& Claude Guimier/Maxi Krause (eds.), Actes du Colloque Autour de la préposition, 76-90. Caen: Presses Universitaires de Caen.

Luraghi, Silvia. 2011. The coding of spatial relations with human landmarks. In Seppo Kittilä \& Katja VästiJussi Ylikoski (eds.), Case, animacy and semantic roles, 209-234. Amsterdam: John Benjamins.

Maiden, Martin \& Mair Parry (eds.). 1997. The dialects of Italy. London: Routledge.

Malchukov, Andrej \& Andrew Spencer (ed.). 2011. The Oxford handbook of case. Oxford: Oxford University Press. 
Mateu, Jaume. 2002. Argument structure. Relational construal at the syntax-semantics interface. Barcelona: Universitat Autònoma de Barcelona doctoral dissertation.

Matushansky, Ora \& Zwarts Joost. 2019. Tops and bottoms: Axial nominals as weak definites. In Proceedings of WCCFL, vol. 36, 270-280. Somerville, MA: Cascadilla Press.

Medeiros, David. 2017. Case variation in Eastern Polynesian spatial prepositions. Unpublished, California State University.

Merchant, Jason. 2001. The syntax of silence: Sluicing, islands, and the theory of ellipsis. Oxford: Oxford University Press.

Merchant, Jason. 2004. Fragments and ellipsis. Linguistics and Philosophy 27(6). 661-738.

Nam, Senghuo. 1995. The semantics of locative prepositional phrases in English. Los Angeles: UCLA doctoral dissertation.

Napoli, Donna Jo \& Joel Nevis. 1987. Inflected prepositions in Italian. Phonology 4(1). 195-209.

Noonan, Maire. 2010. À to zu. In Guglielmo Cinque \& Luigi Rizzi. (eds.). Mapping spatial P: The cartography of syntactic structures, vol. 6, 161-195. Oxford: Oxford University Press.

Pantcheva, Marina B. 2011. Decomposing path: The nanosyntax of directional expressions. PhD thesis, Universitetet i Troms $\varnothing$.

Peyraube, Alain. 1980. Les constructions locatives en chinois moderne, 21 edn. Paris: Langages croisés.

Polinsky, Maria. 2015. Tsez syntax: A description. Unpublished, Cambridge, MA: Harvard University. Radkevich, Nina. 2010. On location: The structure of case and adpositions. Storr: University of Connecticut doctoral dissertation.

Rakhilina, Elena, \& Teresa Reznikova. 2016. A frame-based methodology for lexical typology. In Pauli Juvonen \& Maria Koptjevskaja-Tamm (eds.), The lexical typology of semantic shifts, 95-129. Berlin: De Gruyter.

Rhee, Seongha. 2004. Grammaticalization of spatio-temporal postpositions in Korean. The Journal of Linguistic Science 31(1). 169-188.

Riemsdijk, Henk van. 1978. A case study in syntactic markedness. Dordrecht: Foris Publications.

Rizzi, Luigi. 1988. Il sintagma preposizionale. In Lorenzo Renzi (ed.), Grande grammatica Italiana di consultazione, vol. 3, 497-530. Bologna: Il Mulino Editore.

Sag, Ivan A., Hans C. Boas \& Paul Kay. 2012. Introducing sign-based construction grammar. In Hans C. Boas \& Ivan A. Sag (eds.), Sign-based construction grammar, 1-31. Stanford: CSLI Publications.

Simmala, Buasawan \& Benjawan Poomsan Becker. 2003. Lao for beginners. Vientane: Paiboon Publishing.

Slobin, Dan I. 1996. Two ways to travel. In Mari Shibatani \& Sandra Thompson (eds.), Grammatical constructions: Their form and meaning, 195-220. Oxford: Clarendon Press.

Slobin, Dan I. 2004. The many ways to search for a frog: Linguistic typology and the expression of motion events. In Sven Strömqvist \& Ludo Verhoeven (eds.), Relating events in narrative, vol. 2. Typological and contextual perspectives, 219-257. Mahwah, NJ: Lawrence Erlbaum Associates.

Stassen, Leon. 2009. Predicative possession. Oxford: Oxford University Press.

Stolz, Thomas. 2007. Lexical typology, lexical contact and creolization. In Wiltrud Mihatsch \& Monika Sokol (ed.), Language contact and language change in the Caribbean and beyond, 19-36. Berlin. Peter Lang.

Stolz, Thomas, Nataliya Levkovych \& Aina Urdze. 2017. When zero is just enough ... In support of a Special Toponymic Grammar in Maltese. Folia Linguistica 51(2). 453-482. 
Stross, Bernard. 1976. Tzeltal anatomical terms: Semantic processes. In Malcolm McClaren (ed.), Mayan linguistics, vol. I, 243-267. Los Angeles: UCLA American Indian Studies Center.

Sun, Chaofen. 2006. Chinese: A linguistic introduction. Cambridge: Cambridge University Press. Svenonius, Peter. 2006. The emergence of axial parts. Nordlyd 33. 49-77.

Svenonius, Peter. 2008. Projections of P. In Anna Asbury, Jacob Dotlačil, Berit Gehrke, Øystein Nilsen \& Rick Nouwen (eds.), The syntax and semantics of spatial P, 63-84. Amsterdam: John Benjamins.

Svenonius, Peter. 2010. Spatial P in English. In Guglielmo Cinque \& Luigi Rizzi (eds.), The cartography of syntactic structures, vol. 6, 127-160. Oxford: Oxford University Press.

Svorou, Soteria. 1994. The grammar of space. Amsterdam: John Benjamins.

Talmy, Leonard. 1978. Figure and ground in complex sentences. In Joseph H. Greenberg (ed.), Universals of human language, vol. 4: Syntax, 625-649. Stanford: Stanford University Press.

Talmy, Leonard. 1983. how language structures space. In Herbert Pick \& Linda Acredolo (eds.). Spatial orientation: Theory, research and application, 225-282. Plenum Press, New York.

Talmy, Leonard. 1985. Lexicalization patterns: Semantic structure in lexical forms. In Timothy Shopen (ed.), Language typology and syntactic description, vol. 3: Grammatical categories and the lexicon, 57-149. Cambridge: Cambridge University Press.

Talmy, Leonard. 1988. Force dynamics in language and cognition. Cognitive Science 12(1). 49-100. Talmy, Leonard. 2000. Towards a cognitive semantics. Cambridge, MA: The MIT Press.

Tauli, Valter 1973. Standard Estonian grammar. phonology, morphology, word formation, vol. 1. Studia Uralica et Altaica Upsaliensia 8. Uppsala: Almqvist \& Wiksell.

Terzi, Arhonto. 2010. On null spatial Ps and their arguments. In Guglielmo Cinque \& Luigi Rizzi (eds.), The cartography of syntactic structures, vol. 6: Mapping spatial PPs, 167-187. Oxford: Oxford University Press.

Tseng, Jesse. 2000. The representation and selection of prepositions. Edinburgh: Edinburgh University doctoral dissertation.

Tortora, Christina. 2005. The preposition's preposition in Italian: Evidence for boundedness of space. In Richard Gess \& Eric Rubin (eds.), Theoretical and experimental approaches to Romance linguistics, 307-327. Amsterdam \& Philadelphia: John Benjamins.

Tortora, Christina. 2008. Aspect inside PLACE PPs. In Anna Asbury, Jacob Dotlačil, Berit Gehrke, Øystein Nilsen \& Rick Nouwen (eds.), Syntax and semantics of spatial Ps, 273-301. Amsterdam: John Benjamins.

Tyler, Andrea \& Vyvyan Evans. 2003. The semantics of English prepositions: Spatial scenes, embodied meaning, and cognition. Cambridge: Cambridge University Press.

Ursini, Francesco-Alessio. 2015. On the syntax and semantics of Italian spatial ps. Acta Linguistica Hungarica 63 (1). 63-110.

Ursini, Francesco-Alessio \& Haiping Long. 2020. Chorophorics in the aquilan dialect. Studia Linguistica 73(2). 471-505.

Vandeloise, Claude. 2010. Genesis of spatial terms. In Vyvyan Evans \& Chilton Paul (Eds.), Language, cognition and space: The state of the art and new directions, 171-192. London: Equinox.

Veismann, Ann. 2009. Eesti kaas- ja määrsõnade semantika võimalusi [Semantics of Estonian Adpositions and Adverbs]. Dissertationes Linguisticae Universitatis Tartuensis, vol. 11. Tartu: Tartu University Press.

Verkuyl, Henk \& Joost Zwarts. 1992. Time and space in conceptual and logical semantics: The notion of path. Linguistics 30(5). 483-511. 
Vincent, Nigel. 1999. The evolution of c-structure: Prepositions and PPs from Indo-European to Romance. Linguistics 37(6). 1111-1153.

Wunderlich, Dieter. 1991. How do prepositional phrases fit into compositional syntax and semantics? Linguistics 2(5). 591-621.

Yamada, Fumiko S. 2014. Māori as a phrase-based language. Mānoa: University of Hawai'l at Mānoa doctoral dissertation.

Zhang, Niina Z. 2012. De and the functional expansion of classifiers. Language and Linguistics 13(3). 569-582.

Zhang, Niina. 2017. Adpositions. In Rint Sybesma, Wolfgan Behr, Yueguo Gu, Zev Handel, Charles Huang \& James Myers (eds.), Encyclopaedia of Chinese language and linguistics, 109-127. Leiden: Brill.

Zipf, George K. 1949. Human behavior and the principle of least effort. London: Addison-Wesley.

Zwarts, Joost. 2005. Prepositional aspect and the algebra of paths. Linguistic and Philosophy 28(6). 699-740.

Zwarts, Joost. 2008. Aspects of a typology of direction. In Susan Rothstein (ed.), Theoretical and crosslinguistic approaches to the semantics of aspects, 79-106. Amsterdam: John Benjamins.

Zwarts, Joost. 2010. A hierarchy of locations: Evidence from the encoding of direction in adpositions and cases. Linguistics 48(5). 983-1009.

Zwarts, Joost \& Yoad Winter. 2000. Vector space semantics: A model-theoretic analysis of locative prepositions. Journal of Logic, Language and Information 9(2). 169-211. 